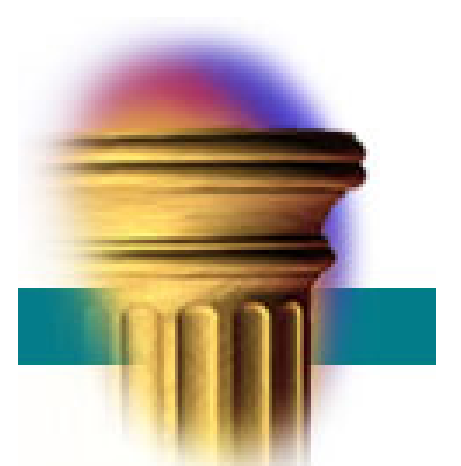

\title{
of \\ The Cross-Section of Labor Leverage and Equity Returns
}

\author{
Andres Donangelo, François Gourio, \\ Matthias Kehrig, and Miguel Palacios
}

\section{September 2016}

\section{WP 2017-22}

\footnotetext{
${ }^{*}$ Working papers are not edited, and all opinions and errors are the responsibility of the author(s). The views expressed do not necessarily reflect the views of the Federal Reserve Bank of Chicago or the Federal Reserve System.
} 


\title{
The Cross-Section of Labor Leverage and Equity Returns*
}

\author{
Andres Donangelo $^{\dagger} \quad$ François Gourio $^{\ddagger} \quad$ Matthias Kehrig $^{\S} \quad$ Miguel Palacios $^{\text {It }}$
}

\begin{abstract}
Using a standard production model, we demonstrate theoretically that, even if labor is fully flexible, it generates a form of operating leverage if (a) wages are smoother than productivity and (b) the capital-labor elasticity of substitution is strictly less than one. Our model supports using labor share-the ratio of labor expenses to value added-as a proxy for labor leverage. We show evidence for conditions (a) and (b), and we demonstrate the economic significance of labor leverage: High labor-share firms have operating profits that are more sensitive to shocks, and they have higher expected asset returns.
\end{abstract}

*This version: September 2016. We thank Frederico Belo, Jack Favilukis, Lars-Alexander Kuehn, and Daniel Rettl for helpful discussions and comments. We would also like to thank seminar participants at the 2015 EFA Meetings, the 2016 Labor and Finance Group Meeting, and the 2016 SFS Cavalcade Meeting for many helpful comments. The views expressed here are those of the authors and do not necessarily represent those of the Federal Reserve Bank of Chicago or the Federal Reserve System.

${ }^{\dagger}$ Department of Finance, University of Texas at Austin. Address: 1 University Station; B6600, Austin TX 78712. E-mail: andres.donangelo@mccombs.utexas.edu. Phone: (510) 232-6841.

$¥$ Economic Research, Federal Reserve Bank of Chicago. Address: 230 South LaSalle Street, Chicago IL 60604. E-mail: fgouriowork@gmail.com. Phone: (312) 322-5627.

${ }^{\S}$ Department of Economics, Duke University. Address: 237 Social Sciences, Durham, NC 27708. E-mail: matthias.kehrig@duke.edu. Phone: (919) 660-1901.

IFinance Department, Vanderbilt University. Address: 401 21st Avenue South, Nashville, TN 37203. E-mail: miguel.palacios@owen.vanderbilt.edu. Phone: (615) 322-8059. 
Labor compensation is the largest expense for firms: Despite its documented secular decline, labor share still represents over $50 \%$ of the gross domestic product (GDP) in the United States. ${ }^{1}$ Magnitude, however, is not the only distinguishing property of labor compensation. For asset pricing, an arguably equally important property of labor compensation is its smoothness relative to firms' cash inflows. This smoothness leads to a labor-induced form of operating leverage (henceforth labor leverage), which amplifies firm risk in a way that is analogous to financial leverage. While financial leverage has been extensively studied, there has been less study on labor leverage, likely because a theoretically supported empirical proxy is lacking. This paper fills this gap and provides theoretical support and empirical validation for labor share (i.e., the ratio between labor expenses and the value added by a firm) as a new measure of firm-level labor leverage. Moreover, this paper presents new evidence for the economic significance of labor leverage in explaining cross-sectional differences in the riskiness of cash flows and asset returns.

We first motivate the theoretical link between labor leverage, labor share, and the cross-section of stock returns in a simple setting. There are two sufficient conditions for the existence of the labor leverage mechanism: (a) Wages must be smoother than shocks to a firm's output (e.g., productivity or demand shocks), and (b) labor and capital must be strict complements in a firm's productive technology. ${ }^{2}$ The data support these two conditions for the existence of labor leverage. Aggregate wages are less volatile than productivity, as is well known in the macroeconomics literature; however, we also document that labor costs are significantly less variable than other costs: For instance, in our sample, a $1.0 \%$ reduction in sales leads, on average, to a $0.6 \%$ reduction in staff (labor) expenses but also leads to a $1.2 \%$ reduction in all other costs. We also provide evidence that the elasticity of substitution between capital and labor is strictly lower than one, which is consistent with a large body of literature in economics. ${ }^{3}$ Specifically, we propose a novel, theoretically motivated procedure to estimate the elasticity of substitution and to obtain point estimates that range from 0.4 to 0.6 , depending on the subsample of Compustat firms used.

\footnotetext{
${ }^{1}$ For instance, Gollin (2002) finds that labor share is between 0.65 and 0.80 across most of the developed countries included in his sample. For a discussion of the global decline in labor share, see Piketty (2014) and Karabarbounis and Neiman (2014).

${ }^{2}$ The widely used Cobb-Douglas productive technology does not allow for this flexibility, since it constrains the elasticity of substitution between labor and capital to unity. As a result, models using Cobb-Douglas production functions do not generate labor leverage.

${ }^{3}$ As discussed by León-Ledesma, McAdam, and Willman (2010); and Klump, McAdam, and Willman (2012); among others, there is strong empirical evidence in the literature that the elasticity of substitution is less than one, especially at the firm level.
} 
We construct two novel alternative firm-level measures of labor share using Compustat data. These two measures are closely related to the measure used in our model. We validate our two alternate measures of labor share by showing that these are in fact positively related to the sensitivity of operating profits to economic shocks. In particular, we show that the sensitivity of profits to real GDP and aggregate TFP shocks is positive for the average firm, and is cross-sectionally increasing in labor share. Consistent with the model, we also find that the sensitivity of profits to aggregate shocks to wages is negative for the average firm and increasing in magnitude in labor shares. However, this result is not significant at conventional levels.

After documenting the relation between labor share and operating leverage, we proceed to study the implications that our proposed mechanism holds for expected returns. Our theory predicts a positive relation between labor share and expected returns, as long as a firm's productivity has a greater systematic risk loading than its wage rate. An equivalent sufficient condition is the greater volatility and procyclicality of productivity with respect to wages. To address the challenge that expected returns are not directly observable in the data, we use two different types of proxies for expected returns: realized asset returns and systematic risk loadings (i.e., betas on risk factors). We find supporting evidence that expected asset returns are increasing in labor share. In particular, we find that high labor share firms earn, on average, higher realized asset returns, and we find that these firms have higher betas.

We next show that a production model that nests our simple general setting is able to generate results that are not only qualitatively but also quantitatively consistent with what we observe in the data. We present such a model and calibrate it using standard moments for risky-asset returns, as well as novel moments presented in the empirical section such as the elasticity of substitution between labor and capital. This calibration delivers a set of results that closely match relevant moments found in the data, giving credence to our proposed mechanism. The success of the calibration of the model also supports the hypothesis that labor leverage is a first-order driver of cross-sectional variation of firms' exposure to fundamental sources of risk and thus of crosssectional variation in expected returns.

This paper considers the simplest set of conditions that would generate a positive labor leverage that varies across firms. However, it is important to note that many other mechanisms can generate similar results. ${ }^{4}$ We view alternative mechanisms as complementary, since multiple channels are

\footnotetext{
${ }^{4}$ Examples of alternative mechanisms that drive labor cost smoothness include: labor contracts that insure workers (e.g., Danthine and Donaldson (2002), Berk and Walden (2013), and Favilukis and Lin (2016)), unionization (e.g.,
} 
likely present in reality. Regardless of the channel, previous literature has not empirically documented the relation between labor leverage and asset prices. The most significant contribution of our paper is the empirical evidence we provide for this relation.

This paper contributes to the literature that studies the relation between operating leverage and stock returns. ${ }^{5}$ Within this literature, our paper is more closely related to the strand that discusses the relation between labor-induced forms of operating leverage and asset prices. Examples of this literature include Danthine and Donaldson (2002); Belo, Lin, and Bazdresch (2014); Donangelo (2014); Zhang (2014); and Favilukis and Lin (2016). Danthine and Donaldson (2002) discuss a mechanism in which countercyclical capital-to-labor share leads to labor-induced operating leverage in a general equilibrium setting. In their model, wages are less volatile than profits, due to the limited market participation of workers, and firms insure workers through labor contracts against labor risk. Stable wages act as an extra risk factor for shareholders, as markets are incomplete in their model. Donangelo (2014) proposes a model that establishes a positive connection between labor mobility and labor leverage. Labor intensity and labor mobility are two complementary mechanisms that affect a firm's operating leverage. In a cyclical industry, the effect of labor mobility on firm risk is increasing in labor share, and the effect of labor share on firm risk is increasing in labor mobility. Most recently, Zhang (2014) derives predictions similar to our model based on the optimal implicit contract between workers and firms. Overall, the key difference is that our model dynamics stems from simple "spot" labor markets with realistic assumptions about labor demand and labor supply, while this literature focuses on "implicit contracts" and the ensuing insurance arrangements. We view these analyses as complementary, since both channels are likely present in reality. ${ }^{6}$

Chen, Kacperczyk, and Ortiz-Molina (2012)), and labor mobility (e.g., Donangelo (2014)).

${ }^{5}$ Some examples of this literature that focuses on the traditional (i.e., non labor-induced) form of operating leverage include: Lev (1974); Mandelker and Rhee (1984); Carlson, Fisher, and Giammarino (2004); Zhang (2005); and Novy-Marx (2011).

${ }^{6}$ Other papers that relate labor to finance issues are Peterson (1994); Santos and Veronesi (2006); Merz and Yashiv (2007); Chen and Zhang (2011); Chen et al. (2012); Eisfeldt and Papanikolaou (2013); Petrosky-Nadeau, Zhang, and Kuehn (2013); Kuehn, Simutin, and Wang (2014); Schmidt (2014); Favilukis, Lin, and Zhao (2015); and Favilukis and Lin (2016). 


\section{Theoretical Motivation}

In this section, we present and analyze the labor leverage mechanism, and demonstrate why the labor share is a valid proxy for labor leverage. In the interest of clarity, this section makes many simplifying assumptions and focuses on a two-period setting. The last section of the paper presents and estimates a dynamic model.

Consider a firm that produces value added $Y$ according to

$$
Y_{\mathrm{t}}=X_{\mathrm{t}} F\left[K_{\mathrm{t}}, L_{\mathrm{t}}\right]
$$

where $X$ denotes the firm's total factor productivity (TFP), $L$ denotes labor, $K$ denotes capital, and F represents an homogeneous function of degree $1 .^{7}$ The firm takes the wage rate $W$, which is set in an implicit perfect labor market. Capital adjustment costs are sufficiently high as to make it constant in the instant considered, $K_{\mathrm{t}}=K$. The firm's profit maximization problem at time t defines optimized operating profits $\Pi$ as given by

$$
\Pi_{\mathrm{t}}=\max _{L_{\mathrm{t}}}\left\{X_{\mathrm{t}} F\left[K, L_{\mathrm{t}}\right]-L_{\mathrm{t}} W_{\mathrm{t}}\right\}
$$

where $W$ denotes the market wage, which is possibly correlated with the firm's TFP. We define labor leverage as the (rescaled) ratio of the elasticity of operating profit to productivity and the elasticity of value added to productivity. ${ }^{8}$ Formally,

Proposition 1 (Labor Leverage)

For a constant-returns-to-scale production function, labor leverage is given by

$$
\ell \equiv \frac{d \Delta \pi_{\mathrm{t}} / d \Delta x_{\mathrm{t}}}{d \Delta y_{\mathrm{t}} / d \Delta x_{\mathrm{t}}}-1=\frac{(1-\gamma) \frac{S_{\mathrm{t}}}{1-S_{\mathrm{t}}}\left(1-\frac{\partial \Delta w_{\mathrm{t}}}{\partial \Delta x_{\mathrm{t}}}\right)}{1+\gamma \frac{S_{\mathrm{t}}}{1-S_{\mathrm{t}}}\left(1-\frac{\partial \Delta w_{\mathrm{t}}}{\partial \Delta x_{\mathrm{t}}}\right)}
$$

\footnotetext{
${ }^{7}$ That is, the production technology has the constant-returns-to-scale property. Also, note that we refer throughout the paper to $X$ as TFP for simplicity, but it may actually also capture shifts in the demand for the product.

${ }^{8}$ The intuition behind this definition is that labor leverage captures the extent to which productivity or demand shocks are transformed into operating income shocks. Note that the definition of labor leverage in this setting is analogous to the definition of the broader operating leverage (e.g., see Garcia-Feijoo and Jorgensen (2010)). The reason is that, in our setting, only labor leads to operating leverage. In the Appendix we briefly discuss the case in which the firm is also subject to fixed operating costs to illustrate how the definition of labor leverage is nested within the broader definition of operating leverage.
} 
where $\gamma_{\mathrm{t}} \equiv \frac{F_{\mathrm{K}}\left[K_{\mathrm{t}}, L_{\mathrm{t}}\right] F_{\mathrm{L}}\left[K_{\mathrm{t}}, L_{\mathrm{t}}\right]}{F\left[K_{\mathrm{t}}, L_{\mathrm{t}}\right] F_{\mathrm{KL}}\left[K_{\mathrm{t}}, L_{\mathrm{t}}\right]}$ is the elasticity of substitution between labor and capital, $S \equiv \frac{L W}{Y}$ is labor share, and lower-case variables are expressed in logs (e.g., $\left.\Delta x_{\mathrm{t}} \equiv \log \left[X_{\mathrm{t}} / X_{\mathrm{t}-1}\right]\right)^{9}{ }^{9}$

Proposition (1) shows that labor leverage is a function of the firm's labor share, the elasticity of substitution of capital and labor, and the response of wages to productivity changes. In particular, note that if wages respond one-for-one with productivity (i.e., $\frac{\partial \Delta w_{t}}{\partial \Delta x_{t}}=1$ ), then all firms have zero labor leverage. Hence, smooth wages are a necessary condition for labor leverage to exist.

The following assumptions are necessary and sufficient for the existence of strictly positive labor leverage in our setting:

Assumption 1 (Smoothness of Wages and Strict Complementarity of Labor and Capital)

a. Wages are smooth relative to productivity: $\frac{\partial \Delta w_{\mathrm{t}}}{\partial \Delta x_{\mathrm{t}}}<1$.

b. The elasticity of substitution between labor and capital is less than one: $\gamma<1$.

It is common to assume a Cobb-Douglas production function, $F(K, L)=K^{\alpha} L^{1-\alpha}$. In this case, labor share is constant, profits are a constant share of output, $\Pi=(1-\alpha) Y$; hence the elasticity of profit equals the elasticity of value added, so that labor leverage $\ell=0$. However, as the next proposition shows, this case turns out to be knife-edged (and, as we will argue later, not empirically relevant).

The proposition that follows shows that Assumption 1 represents a set of necessary and sufficient conditions for the validity of labor share as its proxy.

Proposition 2 (Labor Leverage and Labor Share)

Assumption 1 implies:

a. The existence of labor-induced operating leverage: $\frac{\partial \Delta \pi_{i} / \partial \Delta_{i}}{\partial \Delta y_{i} / \partial \Delta x_{i}}>1$

b. Labor-induced operating leverage increasing in labor share: $\frac{\partial\left(\frac{\partial \Delta \pi_{\pi} / \partial \Delta_{\mathrm{t}}}{\partial \Delta y_{\mathrm{i}} / \partial \Delta_{\mathrm{i}}}\right)}{\partial S_{\mathrm{t}}}>0$

The corollary below shows how the capital-labor elasticity of substitution is related to the elasticities of value added growth and operating profit growth to shocks.

\footnotetext{
${ }^{9}$ The subscripts $\mathrm{K}$ and $\mathrm{L}$ denote partial derivatives with respect to labor and capital. The proposition follows from the fact that $\frac{d \Delta \pi_{i} / d \Delta \Delta_{i}}{d \Delta \Delta_{i} / d \Delta x_{i}}=\frac{\partial \Delta \pi_{i} / \partial \Delta x_{i}+\left(\partial \Delta \pi_{i} / \partial \Delta w_{i}\right)\left(\partial \Delta w_{i} / \partial \Delta_{i}\right)}{\partial \Delta y_{i} / \partial \Delta x_{i}+\left(\partial \Delta \Delta_{i} / \partial \Delta w_{i}\right)\left(\partial \Delta w_{i} / \partial \Delta x_{i}\right)}$.
} 
Corollary 1 (Useful Relation Involving Capital-Labor Elasticity of Substitution)

The elasticities of value added growth and operating profits growth to shocks are linearly related through the elasticity of substitution between labor and capital, as given by

$$
\partial \Delta y_{\mathrm{t}} / \partial \Delta x_{\mathrm{t}}-1=\gamma\left(\partial \Delta \pi_{\mathrm{t}} / \partial \Delta x_{\mathrm{t}}-1\right) .
$$

We will later use the relation formalized in Corollary 1 to estimate the elasticity of substitution between labor and capital in the data.

So far, the discussion shows that labor leverage makes operating profits relatively more sensitive to shocks. In order for labor leverage to also lead to higher expected returns, we should consider the relative systematic risk exposure of TFP $X$ and wages $W$. For simplicity, here we make the additional simplifying assumptions that there are only two periods and that the economy has a single source of priced risk. ${ }^{10}$ Let $M$ denote the value of an asset that is only exposed to priced risk and that has a risk loading $\beta^{\mathrm{M}}=1$. Let $\beta_{\mathrm{t}}^{\mathrm{X}} \equiv \frac{\partial \Delta x_{\mathrm{t}}}{\partial \Delta m_{\mathrm{t}}}$ and $\beta_{\mathrm{t}}^{\mathrm{W}} \equiv \frac{\partial \Delta w_{\mathrm{t}}}{\partial \Delta m_{\mathrm{t}}}$ denote the systematic risk loadings of portfolios of securities that perfectly replicate TFP growth and wage growth.

Assumption 2 (Positive and high systematic risk loading of TFP relative to wages) $\beta_{\mathrm{t}}^{\mathrm{X}}>0$ and $\beta_{\mathrm{t}}^{\mathrm{X}}>\beta_{\mathrm{t}}^{\mathrm{W}}$.

The proposition below shows that Assumption 2 implies that asset betas are increasing in labor share.

Proposition 3 (Systematic Risk Exposure and Labor Share)

a. Cash flow beta: $\beta_{\mathrm{t}} \equiv \frac{\partial \Delta \pi_{\mathrm{t}}}{\partial \Delta x_{\mathrm{t}}} \frac{\partial \Delta x_{\mathrm{t}}}{\partial \Delta m_{\mathrm{t}}}+\frac{\partial \Delta \pi_{\mathrm{t}}}{\partial \Delta w_{\mathrm{t}}} \frac{\partial \Delta w_{\mathrm{t}}}{\partial \Delta m_{\mathrm{t}}}=\beta_{\mathrm{t}}^{\mathrm{X}}+\frac{S_{\mathrm{t}}}{1-S_{\mathrm{t}}}\left(\beta_{\mathrm{t}}^{\mathrm{X}}-\beta_{\mathrm{t}}^{\mathrm{W}}\right)$.

b. Assumption 2 implies that $\frac{\partial \beta_{\mathrm{t}}}{\partial S_{\mathrm{t}}}>0$.

\section{Empirical Evidence}

We first summarize our testable hypothesis. We then discuss how we construct the labor share variable. Next, we present evidence for the smoothness of labor costs, the strict complementarity between labor and capital, and for the sensitivity of profits to aggregate shocks as increasing in labor share. At the end of this section, we explore the cross-sectional relation between labor share and expected returns.

\footnotetext{
${ }^{10}$ We chose the two-period setting simply because it is very tractable: In this particular case, equity betas equal cash-flow betas. We relax this assumption in the dynamic production-based model presented at the end of this paper.
} 


\subsection{Testable Hypothesis}

This section presents empirical support for main testable implications of the theoretical discussion from the previous section: (1) Firms with high labor share exhibit higher sensitivity of cash flows to aggregate shocks (Proposition (2)), and (2) firms with high labor shares have higher expected returns (Proposition (3)).

\subsection{Data}

Our main empirical measure of labor share (hereafter LS) is given by the ratio of labor costs to value added. It is defined from Compustat items as follows:

$$
\mathrm{LS}_{i t} \equiv \frac{\mathrm{XLR}_{i t}}{\mathrm{OIBDP}_{i t}+\mathrm{XLR}_{i t}+\Delta \mathrm{INVFG}_{i t-1, t}},
$$

where $X L R$ is the Compustat variable "Staff Expense - Total" (which we use as a proxy for labor costs), $O I B D P$ is the Compustat variable "Operating Income Before Depreciation," and $\Delta \mathrm{INVFG}_{t-1, t} \equiv \mathrm{INVFG}_{\mathrm{t}}-\mathrm{INVFG}_{t-1}$ is the change in the Compustat variable "Inventories -Finished Goods." We include the change in inventories of final goods to make the empirical measure consistent with the theoretical one. The reason is that, unlike in our model, some of the goods produced over a given year are not sold during that year and, likewise, a portion of the goods sold by the firm in a given year were produced in previous years. ${ }^{11}$

A limitation of the LS measure is that, since the variable $X L R$ is a supplementary income statement item, it is only available for roughly $12 \%$ of firm-year observations in our sample. To address this limitation, we use a second measure, which we denote as "extended" labor share (hereafter ELS). We define ELS as

$$
\mathrm{ELS}_{i t} \equiv \begin{cases}\mathrm{LS}_{i t} & \text { if XLR is non-missing } \\ \mathrm{OIBDP}_{i t}+\mathrm{LABEX}_{i t}+\Delta \mathrm{INVFG}_{i t-1, t} & \text { if } X L R \text { is missing }\end{cases}
$$

where $L A B E X$ is a constructed variable defined as the product of the Compustat variable EMP ("Number of Employees") and the average annual labor compensation per employee in the industry during that year. We estimate the average labor compensation per employee as the average ratio of

\footnotetext{
${ }^{11} \mathrm{We}$ set $\Delta \mathrm{INVFG}_{i t}$ to 0 when either INVFG ${ }_{i t}$ or $\mathrm{INVFG}_{i t-1}$ are missing. The results presented in the paper are qualitatively unaffected by excluding the change in inventories from the measure of labor share.
} 
$X L R$ and EMP in the industry, calculated using the firms that do report $X L R .^{12}$ We exclude from our sample firm-year observations where ELS is negative or greater than one.

Table 1 reports time-series averages of median characteristics for portfolios of firms sorted on LS (Panel A) and ELS (Panel B). We present the statistics both for simple sorts and for withinindustry sorts. (This is motivated by the evidence in Novy-Marx (2011) that intra- as opposed to inter-industry differences in book-to-market ratios are more closely related to cross-sectional variation in operating leverage intensity.) By construction, the second and third columns of Panel A are identical, since ELS is defined as LS in the subsample of firms where the latter is extant. More telling is the fact that the second and third columns of Panel B are quite similar as well. We interpret this fact as evidence that the distribution of ELS conditional on missing LS is not significantly different from the distribution of ELS conditional on non-missing LS. The fourth column reports that the number of employees per unit of plant, property, and equipment (PPE) (which represents an additional measure of labor intensity used in the literature) is increasing in both LS and ELS.

Columns 5 to 11 of the two panels show how firm characteristics vary across labor market quintiles. High labor share firms tend to have higher book-to-market ratios than low labor share firms, particularly in industry-adjusted sorts. Table 1 also shows a negative relation between labor share and both the market value of equity and the book value of assets. The negative trend in the market value of equity is consistent with the hypothesized greater riskiness of high labor share firms. A possible explanation for the negative trend in asset values is a downward bias in asset value reporting, in particular since high labor share firms are both less capital intensive and have less tangible assets. ${ }^{13}$ Consistent with a reporting bias, the panels report that the value of organizational capital, which is not considered in a firm's financial reports, is increasing in labor share. Profitability ratios and (to some extent) financial leverage ratios seem fairly unrelated to labor share. All these patterns are qualitatively similar across our two measures of labor share.

\section{$<<$ Table 1 here $>>$}

\footnotetext{
${ }^{12}$ We use the Fama-French 17-industry category if available. Otherwise, we use the average ratio from the 2-digit SIC industry.

${ }^{13}$ See Damodaran (2011) for a discussion of the relation between intangibles and a bias in asset value reporting.
} 


\subsection{Evidence for the Labor Leverage Mechanism}

In this section, we present empirical support for the existence of the labor leverage mechanism. We start by verifying the two sufficient conditions discussed in the theoretical motivation section. The first condition, which is sufficient for the existence of the labor leverage mechanism, is for wages to be smoother and less procyclical than productivity. We also investigate the smoothness of total labor costs, which is an implication of the model. The second condition is that labor share is countercyclical, or equivalently, that the capital-labor elasticity of substitution is less than one. The two conditions combined guarantee that labor leverage amplifies expected equity returns.

\subsubsection{Evidence for Labor Cost Smoothness}

Table 2 gives some statistics that support the hypothesis that wages are smoother and less procyclical than output, profits, and TFP. The table shows that the volatility of the growth rate of before-tax profits is 3.54 times the volatility of the growth rate of GDP, and the slope coefficient in a regression of profit growth on GDP growth, used as a proxy for procyclicality, is 2.22 . On the other hand, the volatility of real wage growth is 0.51 times that of GDP growth, thus significantly smoother than profits. Moreover, the slope coefficient of wages on GDP growth is 0.14, which supports the assumption that wages are less procyclical than profits. TFP is slightly more volatile (volatility 0.57 times that of GDP growth) and significantly more procyclical (slope coefficient of TFP growth on GDP growth is 0.49 ) than wages. ${ }^{14}$

$$
<<\text { Table } 2 \text { here }>>
$$

Next, we investigate the elasticity of total labor costs to changes in sales directly. The advantage of analyzing labor costs is that we can conduct the analysis at the firm level. Table 3 shows that, for each dollar change in sales, staff expenses change $9 \notin$ while all other operating costs (i.e., the

\footnotetext{
${ }^{14}$ The GDP growth series is taken from Table 1.1.3 of the National Income and Product Accounts of the Bureau of Economic Analysis (www.bea.gov). The real wage series and total factor productivity growth series are annualized, based on the quarterly seasonally adjusted series from the Bureau of Labor Statistics Major Sector Productivity and Costs program (www.bls.gov/lpc). The series cover the non-farm business sector. Following Arias, Hansen, and Ohanian (2007), We compute TFP growth as $\Delta \log T F P=\Delta \log Y-\frac{2}{3} \Delta \log H$, where $\Delta \log Y$ is the real output series and $\log H$ is the hours of all persons series. For business cycle frequencies, taking into account capital does not affect the results. The real wage series is real hourly compensation. This measure is based on the BEA estimates for labor compensation, and it includes benefits. As a result, our measures of real wages and productivity are comparable in sectoral coverage and in construction.
} 
sum of costs of goods sold and sales, general, and administrative expenses minus staff expenses) change $72 \phi$. The table also shows that for each percentage point change in sales, staff expenses change by $0.43 \%$, which is half of the change in all operating expenses $(1.07 \%)$ and a third of that of non-labor operating expenses $(1.46 \%)$. These findings support the hypothesis that labor costs are relatively inelastic, which is consistent with the existence of the labor leverage mechanism.

$$
<<\text { Table } 3 \text { here }>>
$$

\subsubsection{Evidence for the Countercyclicality of Firm-Level Labor Share}

The previous section shows that labor costs are relatively smoother than output and other types of costs. This section takes a step forward and investigates a direct implication of this finding, which is the countercyclicality of firm-level labor share. In order to establish the cyclicality of labor share, we run the following panel data regressions with firm-fixed effects:

$$
S_{\mathrm{i}, \mathrm{t}}^{\mathrm{g}}=\beta_{0, \mathrm{i}}+\beta_{1} x_{\mathrm{t}}^{\mathrm{g}}+\varepsilon_{\mathrm{i}, \mathrm{t}}
$$

where $S^{\mathrm{g}}$ is the annual percentage growth in the measure of labor share under consideration (LS or ELS) and $x^{\mathrm{g}}$ is the percentage growth in our business cycle proxy (GDP growth, TFP growth, or market returns).

Table 4 documents the estimates from regression (6) in our samples of firms with non-missing LS and non-missing ELS. The table shows that our two measures of labor share are in fact timevarying and countercyclical. This result is consistent with the previous finding that wages are smooth and that the capital-labor elasticity of substitution is less than one, since in that case labor share and productivity are negatively related. Moreover, this result indicates that labor leverage is countercyclical and thus potentially significant for asset pricing. But, before investigating the relation between labor share and expected returns, we investigate the hypothesis that labor and capital are strictly complements, which could at least partially explain the relative smoothness of labor costs.

$$
<\text { Table } 4 \text { here }>>
$$




\subsubsection{Evidence for Strict Complementarity Between Labor and Capital}

Recall from our theoretical motivation section that smoothness of wages alone does not guarantee smoothness of labor costs, thus the existence of the labor leverage mechanism proposed in this paper. ${ }^{15}$ Proposition (2) shows that, in a frictionless setting with relatively smooth wages and a perfectly elastic and homogeneous labor supply, labor share is countercyclical and labor costs are smoother than output, but only if capital and labor are strict complements. Before proceeding, we should note that, while our theoretical motivation is based on perfect and homogeneous labor markets, a strict complementarity between labor and capital should make labor and capital smoother even without this assumption. Also, please note that in our theoretical motivation, the strict complementarity between labor and capital does not rule out that labor market imperfections or heterogeneity also explain the labor leverage mechanism.

To estimate the capital-labor elasticity of substitution of firms in our sample, we use the theoretically motivated relation formalized in Corollary (1). In particular, we first estimate the elasticity of value added to aggregate shocks, and the elasticity of operating profit growth to aggregate shocks. We use three proxies for aggregate shocks (i.e., sources of risk that affect the firm): GDP growth, TFP growth, and aggregate market returns. Specifically, we run the time-series regressions given by

$$
\begin{aligned}
\operatorname{prof}_{\mathrm{i}, \mathrm{t}}^{\mathrm{g}} & =\beta_{0, \mathrm{i}}^{\Pi}+\beta_{1, \mathrm{i}}^{\Pi} x_{\mathrm{t}}^{\mathrm{g}}+\varepsilon_{\mathrm{i}, \mathrm{t}}^{\Pi}, \quad \text { and } \\
\operatorname{vadd}_{\mathrm{i}, \mathrm{t}}^{\mathrm{g}} & =\beta_{0, \mathrm{i}}^{\mathrm{Y}}+\beta_{1, \mathrm{i}}^{\mathrm{Y}} x_{\mathrm{t}}^{\mathrm{g}}+\varepsilon_{\mathrm{i}, \mathrm{t}}^{\mathrm{Y}},
\end{aligned}
$$

where $x$ is the aggregate shock (GDP growth, TFP growth, or market returns), prof ${ }^{g}$ is percentage growth of operating profit before interest and depreciation, and vadd ${ }^{g}$ is percentage growth in value added. The use of percentage growth for operating profit restricts the sample to positive observations. We define value added (using the denominators of LS and ELS from (4) and (5)) to be consistent with the proxy for labor share that we use. Note that $\beta_{1}^{\Pi}$ and $\beta_{1}^{Y}$ from regressions (7a) and (7b) are conceptually similar to $\partial \Delta \pi / \partial \Delta x$ and $\partial \Delta y / \partial \Delta x$ from the theoretical section. This fact allows us to use the result from Corollary (1) to estimate the effective capital-labor elasticity of

\footnotetext{
${ }^{15}$ For instance, even with constant wages, labor costs perfectly comove with operating profits in a firm with a constant-return-to-scale Cobb-Douglas production function, making profits proportional to output.
} 
substitution from the data in the cross-sectional second pass:

$$
\left(\hat{\beta}_{1, \mathrm{i}}^{\Pi}-1\right)=\gamma_{0}+\gamma\left(\hat{\beta}_{1, \mathrm{i}}^{\mathrm{Y}}-1\right)+\varepsilon_{\mathrm{i}},
$$

where $\hat{\beta}_{1, \mathrm{i}}^{\Pi}$ and $\hat{\beta}_{1, \mathrm{i}}^{\mathrm{Y}}$ are the estimated slopes from (7a) and (7b).

Table 5 shows the results of the two passes described below. The table shows results for the subsample of non-missing XLR-based value added (Panel A) and the non-missing LABEX-based value added (Panel B). We find that, across the two panels and across the three different proxies for aggregate shock, the estimated effective capital-labor elasticity of substitution ranges from 0.40 to 0.57. This result is consistent with the existing literature and with our hypothesis that labor and capital are strictly complements, which at least partially explains the observed smoothness of labor costs and thus the existence of the labor leverage mechanism.

\subsubsection{Sensitivity of Profits to Macroeconomic Shocks}

So far, we have presented evidence that supports labor share as a proxy for labor leverage. In this section, we take a step further and present evidence that operating profits of high labor share firms are exposed to a higher level of operating leverage. A telltale sign that a firm has a high level of operating leverage (labor induced or otherwise) is a high sensitivity of operating profits (before interest and depreciation) to exogenous shocks. To investigate whether labor share is positively related to the sensitivity of operating profits to shocks, we use three proxies for aggregate sources of shocks that are exogenous to individual firms: GDP growth, TFP growth, and aggregate market returns. Our hypothesis, which is formalized in Proposition (2), is that the sensitivity of profits to such shocks is increasing in labor share. To test this hypothesis we run the following panel data regressions with firm-fixed effects and interaction terms:

$$
\operatorname{prof}_{\mathrm{i}, \mathrm{t}}^{\mathrm{g}}=\beta_{0, \mathrm{i}}+\beta_{1} x_{\mathrm{t}}^{\mathrm{g}}+\beta_{2} x_{\mathrm{t}}^{\mathrm{g}} \times S_{\mathrm{i}, \mathrm{t}}+\beta_{3} S_{\mathrm{i}, \mathrm{t}}+\varepsilon_{\mathrm{i}, \mathrm{t}}
$$

where $x$ is the aggregate shock (GDP growth, TFP growth, or market returns), prof $^{\mathrm{g}}$ is percentage growth of operating profit before interest and depreciation, and $S$ is the proxy of labor share under consideration, LS or ELS.

Table 6 shows the results, which are generally consistent with the hypothesis. The positive exposure of profits to aggregate shocks is positive and increasing in magnitude in labor share. This 
finding suggests that the operating profits of labor intensive firms are more sensitive to aggregate shocks, and it further supports the economic significance of the labor-induced operating leverage mechanism and also the validity of labor share as its proxy.

$$
<<\text { Table } 6 \text { here }>>
$$

\subsection{Expected Asset Returns}

Our theoretical model predicts that, under relatively mild assumptions, expected returns should be increasing in labor share. In this section, we investigate this prediction and explore the empirical relation between labor share and expected returns. To address the challenge that expected returns are not observable, we use two different types of proxies for them: realized stock returns and stock return loadings on risk factors (i.e., betas).

\subsubsection{Realized Asset Returns}

Table 7 presents average post-ranking annual excess equity returns of quintile-portfolios of firms sorted on LS, and ELS, as well as a zero-investment portfolio (H-L portfolio). H-L is a yearly rebalanced portfolio that is long stocks in the highest LS or ELS quintile and short stocks in the lowest LS or ELS quintile. The H-L portfolio earns excess returns of between $4.82 \%$ and $4.06 \%$ per year for LS-sorted portfolios and 3.29\% and 3.25\% per year for ELS-sorted portfolios. Ttests using Newey-West standard errors with four lags confirm that the LS-premium is statistically different from zero, although the ELS-premia is not statistically significant at conventional levels.

$$
<<\text { Table } 7 \text { here }>>
$$

Table 8 provides additional supporting evidence for this finding. The panel reports results of panel data regressions of annual returns on lagged values of LS and ELS. All independent variables are standardized so that they have a mean of 0 and a standard deviation of 1 in the sample. This standardization allows for a more direct comparison of the slopes across specifications. A one standard deviation cross-sectional increase in LS and ELS leads to a cross-sectional increase in annual returns of $1.10 \%$ and $0.69 \%$, respectively, after controlling for financial leverage and the size of the asset base. We do not control for book-to-market ratio and market value, since, as we show in the model, these variables subsume the effect of operating leverage on expected returns. 
Taken together, these results support the economic significance of the relation between labor share and expected asset returns.

$$
<<\text { Table } 8 \text { here }>>
$$

\subsubsection{Risk Factor Loadings}

Under a rational expectation and full information setting, realized asset returns are an unbiased, albeit noisy, proxy for unobservable expected asset returns. ${ }^{16}$ In this section, we use loadings on traditional risk factors (i.e., risk factor betas) as an alternative proxy for expected asset returns. Note, however, that the use of empirical estimates of risk factor betas as proxies for expected returns does not imply that this paper takes a stand on whether the empirical implementations of the CAPM or other traditional asset pricing models are well specified. In fact, our model is agnostic in regard to the source of systematic risk in the economy, which is represented by $d Z^{\Lambda}$ from Equation (10). The only additional required assumption in this section is that the empirical risk factors are merely correlated to the true source(s) of risk in the economy. Under this assumption, empirical estimates of risk factor betas will be positively related to expected asset returns. And in that case, the hypothesis that expected returns are increasing in labor share is equivalent to the hypothesis that systematic risk loadings are increasing in labor share.

Table 9 reports the average conditional betas constructed as in Lewellen and Nagel (2006) for portfolios of firms sorted on both measures of labor shares. The table shows betas with respect to the market portfolio (MKT) as well as the SMB (small minus big) and HML (high minus low) risk factors related to size and value from Fama and French (1993). The table also includes betas with respect to the real macro variables described in Table 2 (e.g., GDP, TFP, and wage growth rates).

Panels A and B of the table show that average MKT, SMB, HML, GDP, and TFP betas are increasing in magnitude across the LS- and ELS-based portfolios, respectively. This finding is consistent with the existence of the labor-induced operating leverage mechanism that amplifies a firm's exposure to aggregate shocks. The difference in the average wage growth beta between the highest and lowest labor share quintiles is positive but not statistically significant. The fact that HML betas are negative and increasing in magnitude across the LS-based (although not ELSbased) portfolios is also consistent with the proposed mechanism, since it implies that loadings on

\footnotetext{
${ }^{16}$ Despite its historical popularity and intuitive appeal, there is a growing concern in the literature is that average realized returns are very noisy and possibly biased proxies for expected returns. See Elton (1999) for a discussion of this concern.
} 
$-H M L$ are positive and increasing. In fact, Kogan and Papanikolaou (2014) suggest that $-H M L$ is a risk factor that is related to investment-specific (IST) shocks and thus carries a negative price of risk. $^{17}$

$$
<<\text { Table } 9 \text { here }>>
$$

\section{Model}

The results from the previous section uncover an empirical link between a firm's labor share and its expected return. We now rationalize those results by replicating them via a structural partial equilibrium model. The model is a specific application of the more general framework presented in Section 1. Some additional structure allows us to estimate moments for quantities and prices and compare them to the empirical results from Section 2. We show that this simple model can explain the main findings presented in Section 2, further highlighting the role of labor leverage in firms' cash flow dynamics and, consequently, in their expected returns.

\subsection{Setup}

We take the stochastic discount factor (SDF) as exogenous. The dynamics of the SDF, which we denote by $\Lambda$, are given by

$$
\frac{d \Lambda_{\mathrm{t}}}{\Lambda_{\mathrm{t}}}=-r d t-\eta d Z_{\mathrm{t}}^{\Lambda}
$$

where $r>0$ is the instantaneous risk-free rate, $d Z^{\Lambda}$ is a Wiener process that represents the single source of systematic risk in the economy, and $\eta$ represents the aggregate price of risk.

We assume perfect competition, so that the firm takes as given both its output price and the real wage it must pay its employees. The dynamics of the real wage $W$ are given by

$$
\frac{d W_{\mathrm{t}}}{W_{\mathrm{t}}}=\mu_{\mathrm{w}} d t+\sigma_{\mathrm{w}} \rho_{\mathrm{w}} d Z_{\mathrm{t}}^{\Lambda}+\sigma_{\mathrm{w}} \sqrt{1-\rho_{\mathrm{w}}^{2}} d Z_{\mathrm{t}}^{\mathrm{W}}
$$

\footnotetext{
${ }^{17}$ IST shocks are shocks that affect the value of investment opportunities but not the value of assets in place. See Papanikolaou (2011); Garleanu, Panageas, and Yu (2012); and Kogan and Papanikolaou (2014) for a discussion of the asset pricing implications of IST shocks.
} 
where $d Z^{\mathrm{W}}$ is a Wiener process orthogonal to $d Z^{\Lambda}$ (i.e., $\mathrm{E}\left[d Z^{\mathrm{W}} d Z^{\Lambda}\right]=0$ ); $\mu_{\mathrm{W}}$ and $\sigma_{\mathrm{W}}$ are the drift and volatility of the wage growth process, respectively; and $\rho_{\mathrm{W}}$ is the priced portion of the wage growth risk.

The firm's productive technology is represented by a constant elasticity of substitution (CES) production function. Value added is given by

$$
Y_{\mathrm{t}}=X_{\mathrm{t}}\left(\alpha L_{\mathrm{t}}^{\rho}+(1-\alpha) K^{\rho}\right)^{\frac{1}{\rho}}
$$

where $L$ and $K$ denote the labor and capital employed in production, $\alpha \in(0,1)$ captures the relative importance of labor in total production, $X$ denotes the level of total factor productivity (TFP), and the parameter $\rho$ determines the elasticity of substitution between capital and labor, $\gamma \equiv \frac{1}{1-\rho}$. The limit $\rho \rightarrow-\infty$ represents the case in which capital and labor are perfect complements, while the other extreme case, $\rho=1$, represents the case in which capital and labor are perfect substitutes. The case in which $\rho \rightarrow 0$ represents the Cobb-Douglas production function. We focus on the empirically relevant case in which labor and capital are strictly complements $(\rho<0) .{ }^{18}$ To focus on the implications of the labor share for firm risk, we abstract away from investment and depreciation so that capital $K$ is fixed.

It is convenient to further decompose the firm's TFP $X$ into two components: aggregate TFP $\left(X^{\mathrm{A}}\right)$ and the idiosyncratic component of TFP $\left(X^{\mathrm{I}}\right)$, such that $X=X^{\mathrm{A}} X^{\mathrm{I}}$. Aggregate TFP $X^{\mathrm{A}}$ follows the diffusion process

$$
\frac{d X_{t}^{\mathrm{A}}}{X_{\mathrm{t}}^{\mathrm{A}}}=\mu_{\mathrm{X}} d t+\sigma_{\mathrm{X}} \rho_{\mathrm{X}} d Z_{\mathrm{t}}^{\Lambda}
$$

while the idiosyncratic component of TFP $X^{\mathrm{I}}$ follows the diffusion process

$$
\frac{d X_{t}^{\mathrm{I}}}{X_{\mathrm{t}}^{\mathrm{I}}}=\sigma_{\mathrm{X}} \sqrt{1-\rho_{\mathrm{X}}^{2}} d Z_{\mathrm{t}}^{\mathrm{X}},
$$

where $d Z^{\mathrm{X}}$ is orthogonal to both $d Z^{\Lambda}$ and $d Z^{\mathrm{W}}$ (i.e., $\mathrm{E}\left[d Z^{\mathrm{X}} d Z^{\Lambda}\right]=0$ and $\mathrm{E}\left[d Z^{\mathrm{X}} d Z^{\mathrm{W}}\right]=0$ ).

\footnotetext{
${ }^{18}$ Multiple studies estimate values for the elasticity of substitution between capital and labor $\gamma$ to be .7 or lower, which implies values for $\rho$ lower than -0.4. See Klump et al. (2012) and references therein to find studies that support the strict complementarity between labor and capital in a number of countries around the world. See Oberfield and Raval (2014) for a recent study about the US manufacturing sector that finds an average elasticity of .5. As demonstrated in that paper (and following the insight of Houthakker (1955)), the micro-level elasticity of substitution (which is relevant for our mechanism) may differ substantially from the macro-level elasticity of substitution.
} 
In addition to idiosyncratic TFP shocks, each firm faces a risk of death, in which the productivity and value of the firm both fall to zero. ${ }^{19}$ Firm death is modeled as a Poisson event with mean arrival rate $\lambda$.

Profit maximization drives the firm to set its labor demand $L^{\mathrm{D}}$ such that the marginal profitability of labor $\left(\frac{d Y}{d L}\right)$ is equated to the real wage $(W)$. Labor demand $L^{\mathrm{D}}$ is given by:

$$
L_{\mathrm{t}}^{\mathrm{D}}=(1-\alpha)^{1 / \rho}\left(\left(\frac{W_{\mathrm{t}}}{\alpha X_{\mathrm{t}}}\right)^{\frac{\rho}{1-\rho}}-\alpha\right)^{-\frac{1}{\rho}}
$$

Equation (15) implies that, consistent with intuition, the firm will demand more labor when its productivity is high relative to the real wage. In what follows, we always assume that the firm sets labor optimally.

We define labor share $S$ as the ratio of labor costs to value added, $S \equiv \frac{L^{\mathrm{D}} W}{Y}$. Intuitively, labor share is a measure of how value added is split between workers and the firm (capital) owners. Using Ito's Lemma we find the dynamics of $S$ :

$$
\frac{d S_{\mathrm{t}}}{S_{\mathrm{t}}}=\mu_{\mathrm{S}} d t+\sigma_{\mathrm{S} \Lambda} d Z_{\mathrm{t}}^{\Lambda}+\sigma_{\mathrm{SW}} d Z_{\mathrm{t}}^{\mathrm{W}}+\sigma_{\mathrm{SX}} d Z_{\mathrm{t}}^{\mathrm{X}}
$$

where: $\quad \mu_{\mathrm{s}} \equiv-\left(\frac{\rho}{\rho-1}\right)\left(\mu_{\mathrm{a}}-\mu_{\mathrm{w}}-\sigma_{\mathrm{a}}^{2}\right)+\left(\frac{\rho}{\rho-1}\right)^{2}\left(\frac{\sigma_{\mathrm{x}}^{2}}{2 \rho}-\rho_{\mathrm{w}} \rho_{\mathrm{x}} \sigma_{\mathrm{w}} \sigma_{\mathrm{X}}+\frac{\sigma_{\mathrm{w}}^{2}}{2 \rho}\right)$,

$$
\sigma_{\mathrm{S} \Lambda} \equiv-\left(\frac{\rho}{\rho-1}\right)\left(\rho_{\mathrm{X}} \sigma_{\mathrm{X}}-\rho_{\mathrm{W}} \sigma_{\mathrm{W}}\right)
$$

$$
\sigma_{\mathrm{sw}} \equiv\left(\frac{\rho}{\rho-1}\right) \sigma_{\mathrm{w}} \sqrt{1-\rho_{\mathrm{w}}^{2}}, \quad \text { and }
$$

$$
\sigma_{\mathrm{SX}} \equiv-\left(\frac{\rho}{\rho-1}\right) \sigma_{\mathrm{X}} \sqrt{1-\rho_{\mathrm{X}}^{2}} \text {. }
$$

Equation (16) implies that labor share is affected differently by shocks to wages and shocks to productivity. In the empirically relevant case in which labor and capital are strictly complements $(\rho<0)$, labor share $S$ is decreasing in idiosyncratic productivity (i.e., $\left.\sigma_{\mathrm{SX}}<0\right) .{ }^{20}$ Equation (16) also shows that, despite the fact that labor demand decreases with wages, the labor share $S$ is increasing

\footnotetext{
${ }^{19}$ The purpose of this additional source of idiosyncratic shocks is solely to stabilize the distribution of firms.

${ }^{20}$ For completeness, it is worth mentioning the two cases that are not considered in this paper. Labor share is constant in the standard Cobb-Douglas production function (i.e., when $\rho \rightarrow 0$ ) and equals $\alpha$. When labor and capital are strictly substitutes (i.e., when $\rho>0$ ), labor share is decreasing in wages and increasing in productivity.
} 
in wages (i.e., $\sigma_{\mathrm{SW}}>0$ ) because the price effect dominates the quantity effect. Figure 1 illustrates the negative relationship between labor share and idiosyncratic productivity and shows the positive relationship between labor share and wages. ${ }^{21}$ Finally, the effect of aggregate productivity (i.e., the priced shock $\lambda$ ) on the labor share reflects a combination of the two effects described above. On the one hand, higher aggregate productivity leads to a lower labor share; but on the other hand, higher aggregate productivity is associated with a higher real wage (according to $\rho_{\mathrm{w}}$ ), which increases the labor share. The overall effect is negative (i.e., $\sigma_{\mathrm{S} \Lambda}<0$ ), provided that real wage response is not too large, which is the empirically relevant case, as we discuss below.
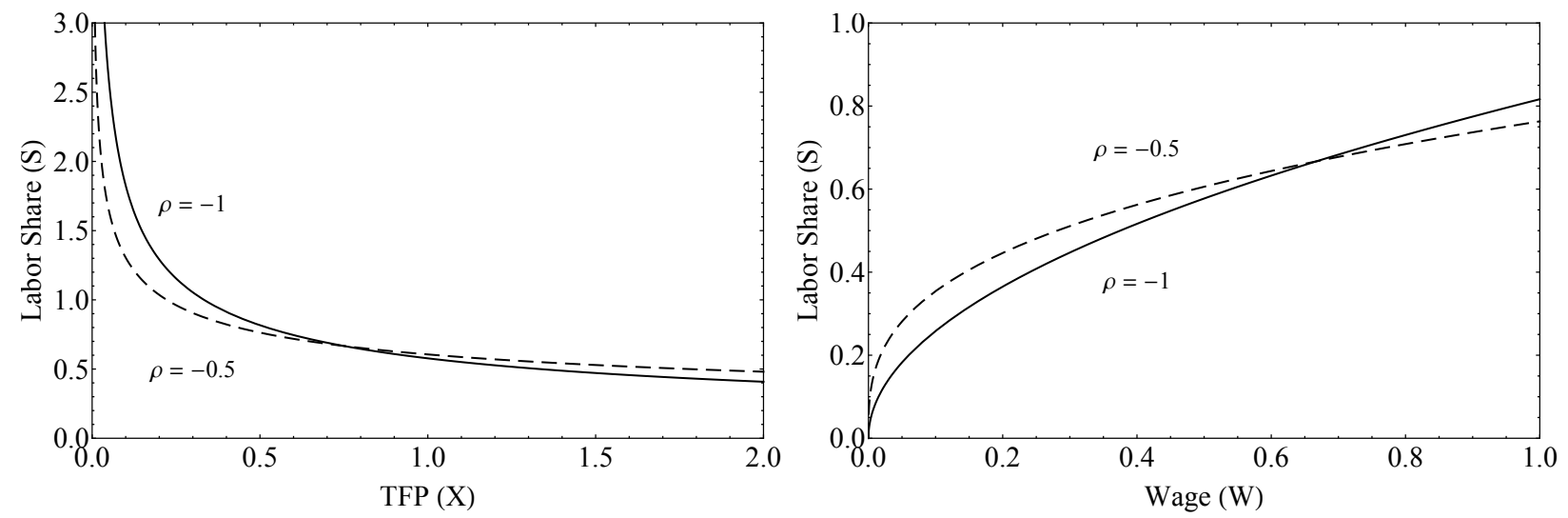

Fig. 1. Determinants of labor share. Labor share as a function of productivity and wages in the production model. The figure shows the numerical solution for the firm's labor share as a function of productivity and wages. The top panel shows that labor share is decreasing in productivity. The bottom panel shows that labor share is increasing in economy-wide wages. The chosen values for $\rho$ result in elasticities of substitution of .5 and .7 , values in the range of what many empirical studies find for the elasticity of substitution between capital and labor. Parameter values used in numerical solution: $\alpha=0.67, W=0.5$ (left panel), and $X=1$ (right panel).

Operating profits are defined as the residual cash flows of the firm after labor expenses are paid, $\Pi \equiv Y-L W$. For simplicity, we assume that firms can frictionlessly suspend and resume production (and thus operating costs) over time. ${ }^{22}$ Operating profits under at the optimal labor demand can then be expressed as a function of productivity $X$ and labor share $S$ :

\footnotetext{
${ }^{21}$ Note that a labor share greater than unity is possible in theory and would simply imply negative operating profits. As we discuss later, shareholders will choose to temporarily suspend operations in such states, so that labor share is effectively bounded by 1 for "active" firms.

${ }^{22}$ If we did not allow this, we would have to allow shareholders to exit the industry, or we would have to assume that limited liability is violated.
} 


$$
\Pi_{\mathrm{t}}= \begin{cases}(1-\alpha)^{\frac{1}{\rho}} X_{\mathrm{t}} K\left(1-S_{\mathrm{t}}\right)^{\frac{\rho-1}{\rho}}, & \text { if } \quad S_{\mathrm{t}}<1 \\ 0, & \text { if } \quad S_{\mathrm{t}} \geq 1\end{cases}
$$

where the second region reflects the fact that the firm will optimally suspend production before operating profits become negative, which happens when $S \geq 1$. Figure 2 shows the negative relation between labor share and operating profits (holding productivity $X$ fixed). For instance, an increase in the real wage leads to an increase in labor share, so that a larger share of revenues is used to compensate labor, and operating profits decline. ${ }^{23}$ On the other hand, higher productivity increases operating profits both by reducing the labor share and by changing the scale of the firm (according to Equation (17)). The dynamics of profit growth are given by:

$$
\frac{d \Pi_{\mathrm{t}}}{\Pi_{\mathrm{t}}}=\mu_{\Pi}\left[S_{\mathrm{t}}\right] d t+\sigma_{\Pi \Lambda}\left[S_{\mathrm{t}}\right] d Z_{\mathrm{t}}^{\Lambda}+\sigma_{\Pi \mathrm{W}}\left[S_{\mathrm{t}}\right] d Z_{\mathrm{t}}^{\mathrm{W}}+\sigma_{\Pi \mathrm{X}}\left[S_{\mathrm{t}}\right] d Z_{\mathrm{t}}^{\mathrm{X}},
$$

where:

$$
\begin{aligned}
\mu_{\Pi}\left[S_{\mathrm{t}}\right] & \equiv\left(\frac{1}{1-S_{\mathrm{t}}}\right)\left(\mu_{\mathrm{x}}-S_{\mathrm{t}} \mu_{\mathrm{W}}+\left(\frac{\rho}{1-\rho}\right)\left(\frac{S_{\mathrm{t}}}{1-S_{\mathrm{t}}}\right)\left(\frac{\sigma_{\mathrm{x}}^{2}}{2}-\rho_{\mathrm{w}} \rho_{\mathrm{x}} \sigma_{\mathrm{w}} \sigma_{\mathrm{x}}+\frac{\sigma_{\mathrm{W}}^{2}}{2}\right)\right), \\
\sigma_{\Pi \Lambda}\left[S_{\mathrm{t}}\right] & \equiv\left(\frac{1}{1-S_{\mathrm{t}}}\right)\left(\rho_{\mathrm{X}} \sigma_{\mathrm{X}}-\rho_{\mathrm{w}} \sigma_{\mathrm{W}} S_{\mathrm{t}}\right), \\
\sigma_{\Pi \mathrm{W}}\left[S_{\mathrm{t}}\right] & \equiv-\left(\frac{S_{\mathrm{t}}}{1-S_{\mathrm{t}}}\right)\left(\sqrt{1-\rho_{\mathrm{w}}^{2}} \sigma_{\mathrm{w}}\right), \quad \text { and } \\
\sigma_{\Pi \mathrm{X}}\left[S_{\mathrm{t}}\right] & \equiv\left(\frac{1}{1-S_{\mathrm{t}}}\right)\left(\sqrt{1-\rho_{\mathrm{X}}^{2}} \sigma_{\mathrm{x}}\right) .
\end{aligned}
$$

Equation (18) shows that, since the capital stock is fixed, the dynamics of operating profits follow only from systematic and idiosyncratic TFP shocks and from shocks to the real wage. It also shows that the sensitivity of profit growth to the three shocks $\left(d Z^{\Lambda}, d Z^{\mathrm{W}}\right.$, and $\left.d Z^{\mathrm{X}}\right)$ are increasing in magnitude in labor share $S$. This fact, which we formalize next, is at the heart of the link between labor share and labor-induced operating leverage.

\footnotetext{
${ }^{23}$ The firm also reacts to the higher real wage by reducing labor demand, but the effect this has on operating profits is zero (to a first order) according to the Envelope theorem (i.e., labor is set optimally).
} 


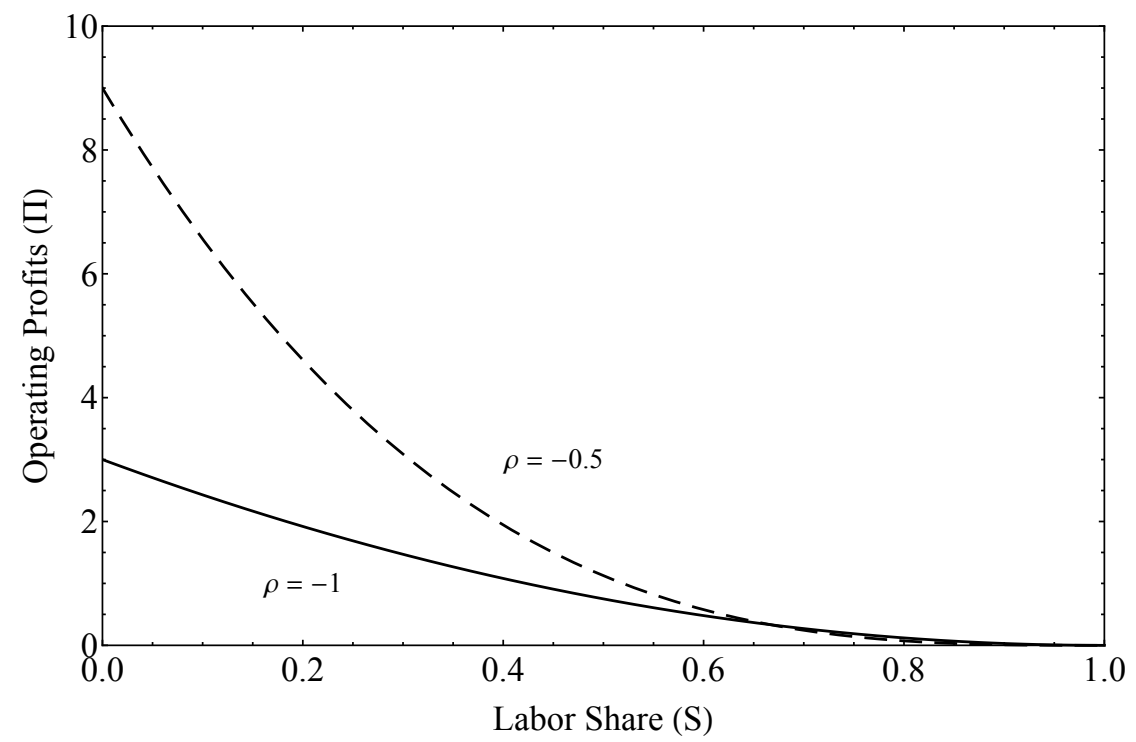

Fig. 2. Operating profits and labor share. Operating profits a function of labor share in the production model. Parameter values used in numerical solution: $W=0.5, \alpha=0.67, K=1, \sigma_{\mathrm{X}}=0.2, \rho_{\mathrm{X}}=0.5, \sigma_{\mathrm{W}}=0.05$, and $\rho_{\mathrm{W}}=0.1$.

\subsection{Labor Leverage}

Having derived the dynamics of cash flows, we can now formalize the labor leverage mechanism. The "traditional" operating leverage arises from the existence of fixed operating expenses. In contrast, the labor leverage mechanism is not based on the existence of fixed costs. (Note that all costs in the model are variable.) Instead, the labor leverage mechanism is based on the relative smoothness of wages and the imperfect correlation between wages and productivity.

To see this, note that the response of profits to the aggregate productivity shock (i.e., the priced shock $\lambda$ ) equals $\left(\frac{1}{1-S}\right)\left(\rho_{\mathrm{X}} \sigma_{\mathrm{X}}-\rho_{\mathrm{w}} \sigma_{\mathrm{w}} S\right)$ according to Equation (18), hence in the special case in which wages respond one-for-one to productivity (i.e., $\rho_{X} \sigma_{X}=\rho_{W} \sigma_{W}$ ), the response of operating profits to the shock is the same for all firms, and it responds one-to-one with the productivity shock. In contrast, in the case in which wages respond less than one-for-one to productivity shocks (i.e., $\rho_{\mathrm{X}} \sigma_{\mathrm{X}}>\rho_{\mathrm{W}} \sigma_{\mathrm{W}}$ ), then the response of operating profits to the shock is greater than 1 for all firms. Firms cash flows "lever up" the smoothness of wages, making operating profits more procyclical. Moreover, this leverage effect is larger when the labor share $S$ is larger.

The assumption $\rho_{\mathrm{X}} \sigma_{\mathrm{X}}>\rho_{\mathrm{W}} \sigma_{\mathrm{W}}$ is consistent with standard stylized facts. In aggregate data, corporate profits (or earnings) are highly procyclical and more volatile than total factor productivity (TFP) or GDP. It is well understood that an important reason for this fact is that labor compensation 
is relatively smooth and weakly correlated with TFP or GDP growth. ${ }^{24}$

To quantify the effect of labor share on firm risk amplification, we define two measures of the sensitivity of operating profits to each of its two sources of shocks: productivity and wages. The first is a measure of the sensitivity of cash flow growth to TFP shocks, $\Theta$, which we denote simply as operating leverage. Operating leverage, $\Theta$, is defined (as in Donangelo (2014)) as the scaled covariance of equilibrium operating profit growth and TFP growth (i.e., $\Theta \equiv \operatorname{Cov}\left[\frac{d \Pi}{\Pi}, \frac{d X}{X}\right] / \operatorname{Var}\left[\frac{d X}{X}\right]-$ 1). ${ }^{25}$ Operating leverage is then given by

$$
\Theta\left[S_{\mathrm{t}}\right]=\frac{S_{\mathrm{t}}}{1-S_{\mathrm{t}}}\left(1-\frac{\rho_{\mathrm{W}} \rho_{\mathrm{X}} \sigma_{\mathrm{W}}}{\sigma_{\mathrm{X}}}\right) .
$$

Equation (19) shows that the sensitivity of operating profits to TFP shocks is positive and monotonically increasing in labor share $S$, as long as TFP is more volatile than the component of wage growth correlated with TFP growth. ${ }^{26}$ This result is summarized in the proposition below:

Proposition 4 (Monotonic relationship between operating leverage and labor share)

The condition $\sigma_{\mathrm{X}}>\rho_{\mathrm{W}} \rho_{\mathrm{X}} \sigma_{\mathrm{W}}$ implies that operating leverage is positive and increasing in labor share $S$ :

$$
\Theta\left[S_{\mathrm{t}}\right]>0 \text { and } \frac{d \Theta\left[S_{\mathrm{t}}\right]}{d S_{\mathrm{t}}} \geq 0
$$

Proposition 4 follows directly from Equation (19). The main message of Proposition 4 is that, under strict complementarity of labor and capital, labor share can be used as a proxy for the degree of labor leverage experienced by the firm.

We also define a related measure $\Theta^{\mathrm{W}}$ as the sensitivity of operating profits to changes in economy-wide wages (i.e., $\Theta^{\mathrm{W}} \equiv \operatorname{Cov}\left[\frac{d \Pi}{\Pi}, \frac{d W}{W}\right] / \operatorname{Var}\left[\frac{d W}{W}\right]-1$ ). The measure $\Theta^{\mathrm{W}}$ is given by

$$
\Theta^{\mathrm{W}}\left[S_{\mathrm{t}}\right]=-\frac{1}{1-S_{\mathrm{t}}}\left(1-\frac{\rho_{\mathrm{w}} \rho_{\mathrm{X}} \sigma_{\mathrm{X}}}{\sigma_{\mathrm{w}}}\right) .
$$

\footnotetext{
${ }^{24}$ For instance, Longstaff and Piazzesi (2004) hypothesize that the reason for the extreme volatility and procyclicality of corporate earnings is that stockholders are residual claimants to corporate cash flows. Thus, the compensation of workers is a senior claim to cash flows. See also Gomme and Greenwood (1995).

${ }^{25}$ Alternatively, $\Theta$ is defined as the slope of a regression of operating profit growth on TFP growth minus one. The subtraction by 1 is a simple rescaling so that $\Theta$ is 0 when there is no risk amplification in the transmission of shocks.

${ }^{26} \mathrm{We}$ anticipate that the assumption is fairly weak. For instance, we document that aggregate wage growth is less volatile and not highly correlated with aggregate TFP growth.
} 
Equation (20) shows that the sensitivity of operating profits to wages shocks is negative, and its magnitude is monotonically increasing in labor share $S$. This result is summarized in the corollary below:

Corollary 1 (Sensitivity of operating profits to wage shocks)

The condition $\sigma_{\mathrm{X}}>\rho_{\mathrm{w}} \rho_{\mathrm{X}} \sigma_{\mathrm{W}}$ implies that the sensitivity of operating profit growth to wage growth is negative and increasing in magnitude in labor share $S$ :

$$
\Theta^{\mathrm{W}}\left[S_{\mathrm{t}}\right]<0 \text { and } \frac{d \Theta^{\mathrm{W}}\left[S_{\mathrm{t}}\right]}{d S_{\mathrm{t}}} \leq 0
$$

Corollary 20 follows directly from Equation (20).

Figure 3 illustrates the relation of labor share to the exposure of operating profits to the two sources of uncertainty: productivity and wages. The figure shows that the magnitudes of the positive sensitivity of operating profits to productivity and the negative sensitivity of operating profits to wage shocks is increasing in labor share. This effect, which is directly related to labor leverage, is an intuitive result: Higher labor share is related to lower profit margins, which buffer the firm against either type of shocks. Productivity is positively related to operating profits, so that the exposure to productivity shocks is always positive and increasing in labor share. Labor expenses are negatively related to operating profits, so that the exposure to wages shocks is always negative, and its magnitude is increasing in labor share.
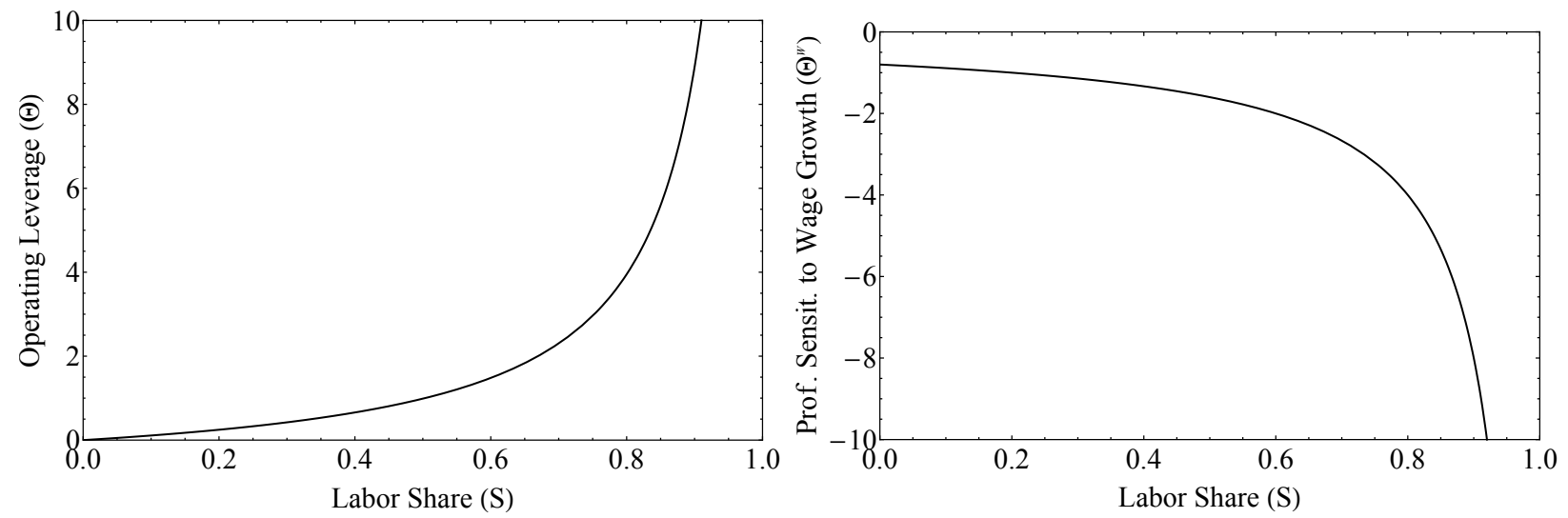

Fig. 3. Labor leverage and labor share. Sensitivity of operating profits to productivity and wage shocks in the production model. The figure shows the relation of labor share to the exposure of operating profits to the two sources of uncertainty: productivity and wages. The figure shows that the magnitudes of the positive sensitivity of operating profits to productivity and the negative sensitivity of operating profits to wage shocks is increasing in labor share. Parameter values used in numerical solution: $W=0.5, \alpha=0.67, K=1, \sigma_{\mathrm{x}}=0.2, \rho_{\mathrm{x}}=0.5, \sigma_{\mathrm{W}}=0.05$, and $\rho_{\mathrm{W}}=0.1$. 


\subsection{Valuation and Expected Returns}

In equilibrium, firm value $(V)$ equals the value of the discounted stream of optimized operating profits:

$$
V_{\mathrm{t}}=\mathrm{E}_{\mathrm{t}}\left[\int_{\mathrm{t}}^{\infty} \frac{\Lambda_{\mathrm{s}}}{\Lambda_{\mathrm{t}}} \Pi_{s} d s\right] .
$$

Under technical conditions, the solution to Equation (21) exists, and it is given by

$$
V_{\mathrm{t}}=(1-\alpha)^{1 / \rho} X_{\mathrm{t}} K v\left[S_{\mathrm{t}}\right]
$$

where $v$ is a monotonically decreasing function of labor share, such that $\lim _{S \rightarrow 0} v[S]=1$ and $\lim _{S \rightarrow 1} v[S]=0$. The explicit solution is given in the Appendix.

The solution for the firm value is intuitive. First, when labor costs become negligible relative to the value added generated by the firm $(S \rightarrow 0)$, the value of the firm converges to that of a firm with a perpetual dividend governed by a geometric Brownian motion, in which the current dividend equals $(1-\alpha)^{1 / \rho} A K$. As the cost of labor increases relative to the value added generated by the firm, the dividend falls and, consistently, the value of the firm falls. When labor costs equal the value added $(S \rightarrow 1)$, operating profits are zero, so the firm shuts down production and all firm value arises from the option to resume production when operating profits become positive again.

The negative relation between labor share and firm value is driven by two complementary channels: a cash flow channel and a discount rate channel. The cash flow channel consists in labor intensive firms having lower operating profits due to higher labor expenses per unit produced (i.e., higher marginal profitability of labor). The discount flow channel is related to the higher loading on systematic risk of a labor-intensive firm relative to a capital-intensive one. Figure 4 illustrates the negative relation between labor share and firm value. 


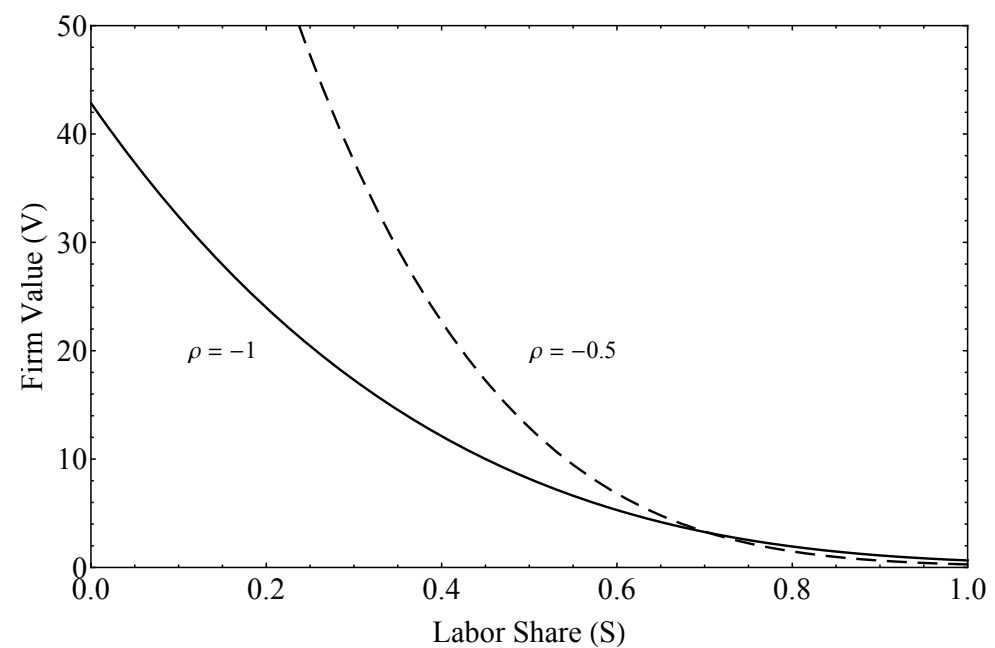

Fig. 4. Firm value and labor share. Firm value as a function of labor share in the production model. Parameter values used in numerical solution: $W=0.5, \alpha=0.67, K=1, \mu_{\mathrm{x}}=0, \sigma_{\mathrm{X}}=0.2, \rho_{\mathrm{x}}=0.5, \mu_{\mathrm{W}}=0, \sigma_{\mathrm{W}}=0.05, \rho_{\mathrm{W}}=0.1$, $r=0.02, \eta=0.5$, and $\lambda=0$.

Expected returns are defined as the instantaneous drift of the gains process that reinvests dividends, $\mathrm{E}_{\mathrm{t}}\left[R_{\mathrm{t}}\right] \equiv \mathrm{E}_{\mathrm{t}}\left[\frac{d V_{\mathrm{t}}+\Pi_{\mathrm{t}}^{*} d t}{V_{\mathrm{t}}}\right]$, and are given by:

$$
\mathrm{E}_{\mathrm{t}}\left[R_{\mathrm{t}}\right]=r-\lambda+\eta \sigma_{\mathrm{X}} \rho_{\mathrm{X}}+S_{\mathrm{t}} \frac{v^{\prime}\left[S_{\mathrm{t}}\right]}{v\left[S_{\mathrm{t}}\right]} \frac{\rho}{1-\rho}\left(\rho_{\mathrm{X}} \sigma_{\mathrm{X}}-\rho_{\mathrm{W}} \sigma_{\mathrm{W}}\right)
$$

We show in the Appendix that $v^{\prime}(s)<0$ holds for all parameter values where a feasible solution for Equation (22) exists. Thus, Equation (23), in conjunction with our assumption that $\rho<0$, implies that the relationship between risk and labor share depends on the sign of $\rho_{X} \sigma_{X}-\rho_{W} \sigma_{W}$. This is formalized below:

Proposition 5 (Asset returns and labor share) For $S_{\mathrm{t}} \in(0,1), \rho_{\mathrm{X}} \sigma_{\mathrm{X}}>\rho_{\mathrm{W}} \sigma_{\mathrm{W}}$ is a sufficient condition for $\frac{d \mathrm{E}_{\mathrm{t}}\left[R_{\mathrm{t}}\right]}{d S_{\mathrm{t}}} \geq 0$.

If the condition is satisfied, wages are less procyclical than productivity, and labor intensivefirms have higher exposure to systematic risk (and narrower profit margins).

Equation (23) shows that the firm's excess returns over the risk-free rate depends on two sources of priced risk. The first source is a premium paid for the riskiness coming from the covariance between the firm's productivity and the stochastic discount factor $\left(\rho_{X} \sigma_{X}\right)$. We call this source of risk productivity risk. Productivity risk affects expected returns both directly, through its impact 
on overall productivity, and indirectly, through its impact on the relative productivity of capital and labor. It is this second, indirect, component that depends on the firm's labor share. The direct impact of productivity risk for an average firm will be positive in good times, as the average firm produces more, or finds that the prices of its products increase. The indirect impact is also positive, since our assumption about complementarity between labor and capital implies that a positive shock to the firm's productivity will amplify the impact on profits.

The second source of risk captures the the firm's exposure to aggregate wages $\left(\rho_{\mathrm{W}} \sigma_{\mathrm{W}}\right)$. We call this component the wage hedge, as it depends only on the firm's exposure to wages and will likely reduce risk for the average firm. The wage hedge is linked to labor share, since variations in wages will have a larger effect on firms for which most of their value added is used to pay for labor. This component is a hedge because, on average, wages fall in bad times, which is precisely when a firm's profits are also falling due to systematic decreases in its own productivity.

Combining the two sources of risk-one positive, the other a hedge-delivers the relation between the firm's labor share and expected returns. This relation will be positive if the firm's systematic component of productivity is procyclical enough relative to wages. For instance, the systematic risk loadings of a firm whose productivity is uncorrelated with the stochastic discount factor $\left(\rho_{\mathrm{X}}=0\right)$ is decreasing in its labor share. This is because, in this case, the hedge effect of wages is uncontested: Wages go up in good times, so profits fall; wages go down in bad times, so the firm's profits increase.

The hedging impact of wages, though, is muted when the firm's productivity is sufficiently procyclical $\left(\rho_{\mathrm{X}} \sigma_{\mathrm{X}}>\rho_{\mathrm{W}} \sigma_{\mathrm{W}}\right)$. In this case, even though wages are a hedge, the procyclical variation in the firm's sales price dominates, making the firm riskier as its labor share increases.

Figure 5 shows that asset betas are increasing in labor shares. The figure also shows that the positive relation between betas and labor share implies a positive relation between betas and wages and implies a negative relation between betas and productivity. The last panel shows that betas are insensitive to productivity once we control for labor share. 

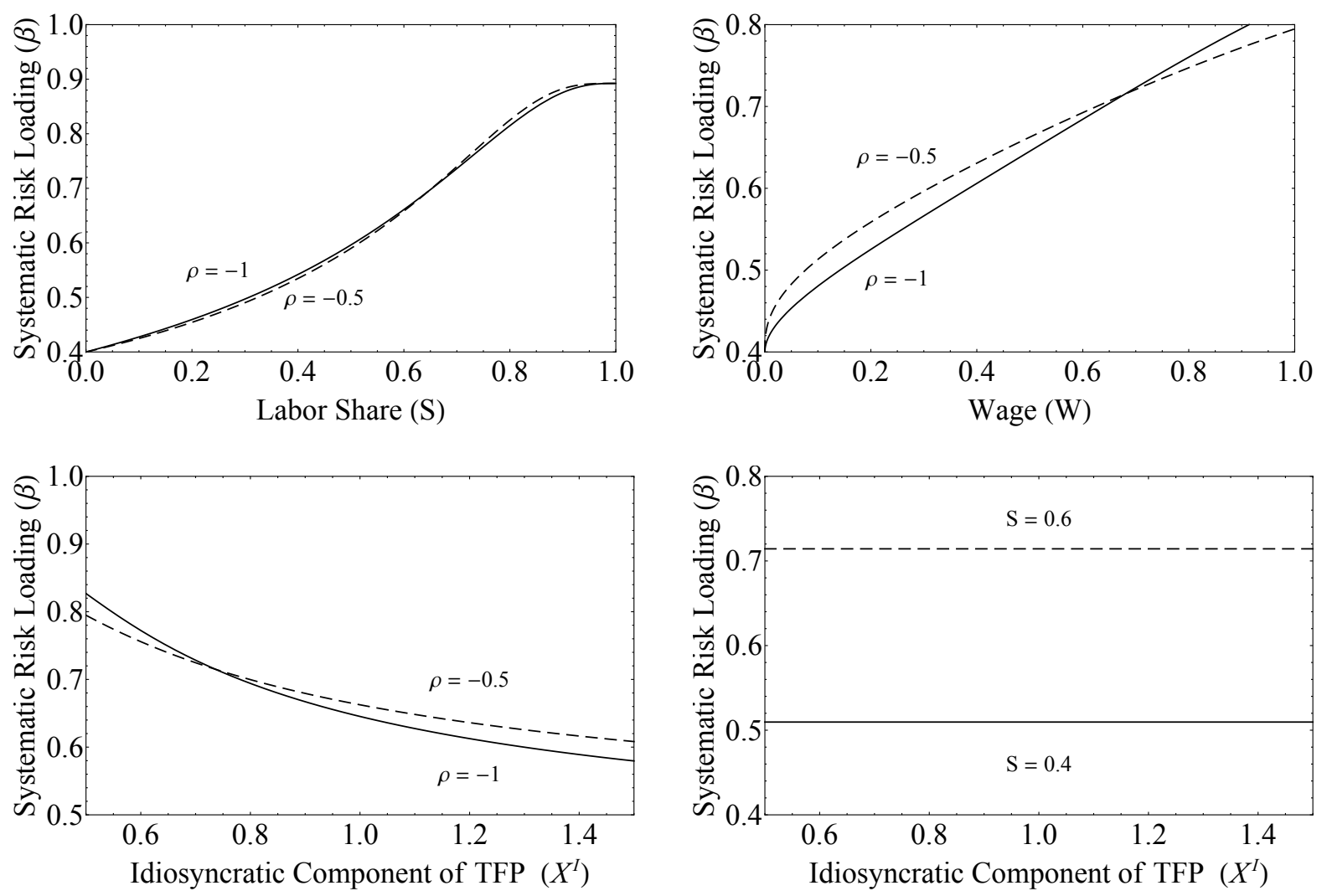

Fig. 5. Betas, productivity, wages and labor share. Betas as a function of labor share, productivity, and wages in the production model. Parameter values used in numerical solution: $X^{\mathrm{I}}=1, X^{\mathrm{A}}=1, W=0.5, \alpha=0.67, K=1, \mu_{\mathrm{X}}=0$, $\sigma_{\mathrm{X}}=0.2, \rho_{\mathrm{X}}=0.5, \mu_{\mathrm{W}}=0, \sigma_{\mathrm{W}}=0.05, \rho_{\mathrm{W}}=0.1, r=0.02, \eta=0.5$, and $\lambda=0$.

\subsection{Quantitative Analysis of the Model}

Our model represents a proof-of-concept for the theory developed in the Section 1. In this section, we take a step further and investigate the quantitative properties of the model via a calibration exercise. By simultaneously simulating the dynamics of many different firms - their labor share, cash flow, valuations, and expected returns endogenously varying over time-we impose discipline on our parameter choice so that relevant moments for the distribution of firms' characteristics match the data. We can then further analyze the model's implications for the cross-section of stock returns, as well as validate some of our indirect measurements from the empirical section, such as the estimation of the elasticity of substitution between labor and capital. We find that, despite its qualitative nature, our model is able to generate results that are consistent with many of 
our empirical findings.

\subsubsection{Calibration procedure}

The calibration exercise is as follows. We use a given set of parameters to generate time-series paths for 10,000 firms over 1,200 months. Firms are identical at the beginning of each simulation. We record firm characteristics and valuations on the penultimate month, and we record returns and volatilities using changes that occurred between the penultimate month and last month in the simulation. Next, we calculate relevant moments for the distribution of firm characteristics and returns, and perform cross-sectional regressions similar to those conducted in Section 2. We repeat this process 10,000 times and then average the resulting moments and coefficients from the regressions. Finally, we compare the moments used for the calibration with the moments found in the data using a loss function and then use a Simulated Annealing algorithm to find parameters that minimize the value of the loss function. ${ }^{27}$

One challenge in the calibration of the model is that the distribution of firm valuations and characteristics is not constant. We deal with this issue in two ways. First, we include a Poisson process for death of firms to the model solution. When a firm dies, it exits the market and it is replaced by a new firm with the same original characteristics that all firms had a time zero. Once we add this feature to the model, long-term distributions will be stationary. Second, the simulated time period is purportedly long to ensure that the distribution of firms becomes stable.

Table 10 shows the target moments used in the calibration. We target macroeconomic moments, firm-level cash flows moments, and firm-level average unlevered stock returns. We choose the macroeconomic moments to ensure that the aggregate behavior of our simulated firms corresponds to well-known aggregate moments of the US economy. In particular, we target the volatilities of GDP, aggregate TFP, and aggregate wage growth. Since covariances are key components of asset prices, we also target the correlations between GDP growth and aggregate TFP growth, the correlation between GDP growth and aggregate wage growth, and the correlation between aggregate TFP growth and aggregate wage growth.

\footnotetext{
${ }^{27}$ The loss function is defined as the weighted average of the squared differences between targets model-generated moments. We only use the last year of simulated data in the analysis to ensure we are measuring the heterogeneity that arises only from differences in the idiosyncratic shock paths. The number of firms chosen for the simulation is set so it is at the same order of magnitude of the average number of publicly traded firms in the United States in the last century. The number of simulations is chosen so that the moments obtained from the simulation are stable enough for the optimal-parameter-seeking algorithm to deliver stable results.
} 
The firm-specific moments we target are those that link labor shares with expected returns through leverage, namely the sensitivity of cash flows to GDP and TFP growth, as well as the change in the sensitivity of cash flows to GDP and TFP growth as a function of labor share.

The asset-pricing moments we target are those that link differences in expected asset returns to labor share. Given that, in the empirical section, we report returns for quintiles of stocks ranked by labor share, we target the average return for the low-labor-share quintile portfolio, the high-laborshare quintile portfolio, as well as the difference in returns between these two portfolios.

Table 10 reports the weights attached to each of the moments targeted in the calibration. We give the highest weight to the aggregate volatility of our simulated firms - with half as much weight on their correlations. We assign a high weight to the cross-sectional standard deviation of valueadded growth, given the relatively low number of other firm-level moments. We set a relatively low weigh to the slope coefficients from the regressions, since these are subject to significantly more serious estimation problems. Finally, we give a relatively high weight to the return of the low-labor-share quintile portfolio to obtain realistic stock returns, and we give a lower weight to the spread in portfolio returns between high and low labor share firms, given that this difference also suffers from potential estimation problems.

$$
<<\text { Table } 10 \text { here }>>
$$

\subsubsection{Calibration results}

Table 11 shows the resulting parameters that are required to match the moments discussed above. Consider first the implications for the "representative" technology in the economy; in particular the elasticity of substitution between capital and labor, given the wide attention it has received in the literature. The resulting parameter, .40, is squarely in the range of values obtained by other estimations performed with very different methodologies, and very close to our own estimate derived in the empirical section.

The calibration delivers the expected results for the observed shocks and drift for wage growth and productivity growth in the U.S., but it yields interesting results related to unobservable variables: in particular, the priced portion of wage and productivity shocks. The implied priced portion of wage shocks with the stochastic discount factor is .535 , a value that, combined with a wage volatility of .021 and a price of risk of .80 , implies a risk-premium for a claim to aggregate wages of about $.8 \%$. This result is consistent with the common assumption about human capital being a 
"low-risk" asset. The implied priced portion of productivity shocks, .384, suggests that the largest component of the productivity shocks received by firms is purely idiosyncratic.

Finally, the calibration implies a risk-free rate of $1 \%$ and a Sharpe ratio of .8. These values, particularly the risk-free rate, fall within the range of their widely-used estimates. Note that the only asset pricing moments we used were the average returns of the low- and high-labor-share portfolios. So we consider it a success that the calibration aligns with empirical observations for the risk-free rate and the market price of risk.

$$
<<\text { Table } 10 \text { here }>>
$$

Beyond point estimates for certain parameters, the calibration can be used to investigate the model's capacity to replicate other relevant data. Table 12 contrasts a large number of moments derived from the calibration with those found in the data. Those explicitly targeted in the calibration are presented in bold, while the remaining ones are not targeted.

Table 12, Panel A, contrasts moments for macroeconomic variables in the data and in the model. We highlight the result for the comovement — captured as a slope coefficient—of wage and GDP growth. The model delivers a coefficient of .171, which implies that wages are relatively "smooth" in the model, just as they are in the data. This is relevant because wage "smoothness" is one of the conditions we identify in Section I as being conducive to labor leverage.

Panels B and C contain moments related to the cross-section of firm cash flows. Since we target the cross-sectional standard deviation of firm-level value-added growth, it is not surprising that the resulting moment in the data is close to that one in the data. We do not explicitly target the average and the standard deviation of labor share, which is a moment our model must match in order to be credible. Fortunately, Panel $\mathrm{C}$ shows that our model does match this.

Panels D and E contrast the model and the resulting data for the sensitivities relevant to the labor leverage mechanism. The elasticity of substitution between capital and labor was not one of the calibrated parameters. Hoever, the fact that the estimated value for this elasticity (0.405) is remarkably close to the value used as input $(0.40)$, is useful at validating our proposed new estimation methodology based solely on a panel of firm-level cash flow data.

Finally, Panel F links asset prices related to labor leverage found in the data with those found in the model. The model and the data imply a spread of $1.89 \%$ between high- and low-labor-share portfolios. Panel F closes our exercise by closely replicating the returns of portfolios sorted by labor share. 
Taken as a whole, the results summarized in Table 12 imply that our simple, partial equilibrium model for firm dynamics, relating labor share and asset returns via a labor leverage mechanism, succeeds in explaining the patterns for returns observed in the data.

$$
<<\text { Table } 12 \text { here }>>
$$




\section{Conclusion}

This paper proposes that labor share is a promising new firm characteristic that explains the cross-section of returns. We develop a simple production-based model of a firm to study the labor leverage mechanism. This model provides theoretical motivation for the use of labor share as a firm-level measure of the degree of labor leverage. The model shows that the two sufficient conditions for the use of labor share as a proxy for labor leverage are: (a) Labor and capital are strict complements, and (b) economy-wide wages are smoother than aggregate productivity. These two sufficient conditions are generally supported in the data. Moreover, this paper provides modelagnostic empirical evidence that validates labor share as a measure of labor leverage. In particular, we document that the sensitivity of operating profits to shocks is cross-sectionally increasing in labor share. We further confirm a positive relation between labor leverage and expected asset re-

turns. For instance, we show that average realized stock returns and average loadings on traditional systematic risk factors are increasing in labor share. 


\section{REFERENCES}

Arias, Andres, Gary D. Hansen, and Lee E. Ohanian, 2007, Why have business cycle fluctuations become less volatile?, Economic Theory 32, 43-58.

Belo, Frederico, Xiaoji Lin, and Santiago Bazdresch, 2014, Labor hiring, investment and stock return predictability in the cross section, Journal of Political Economy 122, 129-177.

Berk, Jonathan B., and Johan Walden, 2013, Limited Capital Market Participation and Human Capital Risk, Review of Asset Pricing Studies 3, 1-37.

Carlson, Murray, Adlai Fisher, and Ron Giammarino, 2004, Corporate investment and asset price dynamics: Implications for the cross-section of returns, Journal of Finance 59, 2577-2603.

Chen, Huafeng, Marcin Kacperczyk, and Hernan Ortiz-Molina, 2012, Do nonfinancial stakeholders affect the pricing of risky debt? Evidence from unionized workers, Review of Finance 347383.

Chen, L., and L. Zhang, 2011, Do time-varying risk premiums explain labor market performance?, Journal of Financial Economics 99, 385-399.

Damodaran, Aswath, 2011, The little book of valuation: how to value a company, pick a stock and profit (John Wiley \& Sons).

Danthine, Jean-Pierre, and John B. Donaldson, 2002, Labor relations and asset returns, Review of Economic Studies 69, 41-64.

Donangelo, Andres, 2014, Labor mobility: Implications for asset pricing, Journal of Finance 68, 1321-1346.

Eisfeldt, Andrea L., and Dimitris Papanikolaou, 2013, Organization Capital and the Cross-Section of Expected Returns, Journal of Finance 68, 1365-1406.

Elton, Edwin J., 1999, Presidential address: Expected return, realized return, and asset pricing tests, Journal of Finance 54, 1199-1220.

Fama, Eugene F., and Kenneth R. French, 1993, Common risk factors in the returns on stocks and bonds, Journal of Financial Economics 33, 3-56. 
Favilukis, Jack, and Xiaoji Lin, 2016, Wage Rigidity: A Solution to Several Asset Pricing Puzzles, Review of Financial Studies 29, 148-192.

Favilukis, Jack, Xiaoji Lin, and Xiaofei Zhao, 2015, The Elephant in the Room: the Impact of Labor Obligations on Credit Risk, working paper .

Garcia-Feijoo, Luis, and Randy D. Jorgensen, 2010, Can Operating Leverage Be the Cause of the Value Premium?, Financial Management 39, 1127-1153.

Garleanu, Nicolae, Stavros Panageas, and Jianfeng Yu, 2012, Technological Growth and Asset Pricing, Journal of Finance 67, 1265-1292.

Gollin, Douglas, 2002, Getting income shares right, Journal of Political Economy 110, 458-474.

Gomme, Paul, and Jeremy Greenwood, 1995, On the cyclical allocation of risk, Journal of Economic dynamics and control 19, 91-124.

Houthakker, Hendrik S., 1955, The Pareto distribution and the Cobb-Douglas production function in activity analysis, Review of Economic Studies 27-31.

Karabarbounis, Loukas, and Brent Neiman, 2014, The Global Decline of the Labor Share, Quarterly Journal of Economics 129, 61-103.

Klump, Rainer, Peter McAdam, and Alpo Willman, 2012, The normalized CES production function: theory and empirics, Journal of Economic Surveys 26, 769-799.

Kogan, Leonid, and Dimitris Papanikolaou, 2014, Growth opportunities, technology shocks, and asset prices, Journal of Finance 69, 675-718.

Kuehn, Lars-Alexander, Mikhail Simutin, and Jessie Jiaxu Wang, 2014, A Labor Capital Asset Pricing Model.

León-Ledesma, Miguel A., Peter McAdam, and Alpo Willman, 2010, Identifying the elasticity of substitution with biased technical change, American Economic Review 100, 1330-1357.

Lev, Baruch, 1974, On the Association Between Operating Leverage and Risk, Journal of Financial and Quantitative Analysis 627-641. 
Lewellen, Jonathan, and Stefan Nagel, 2006, The conditional CAPM does not explain asset-pricing anomalies, Journal of Financial Economics 82, 289-314.

Longstaff, Francis A., and Monika Piazzesi, 2004, Corporate earnings and the equity premium, Journal of Financial Economics 74, 401-421.

Mandelker, Gershon N., and S. Ghon Rhee, 1984, The Impact of the Degrees of Operating and Financial Leverage on Systematic Risk of Common Stock, Journal of Financial and Quantitative Analysis 19, 45-57.

Merz, Monika, and Eran Yashiv, 2007, Labor and the Market Value of the Firm, American Economic Review 97, 1419-1431.

Novy-Marx, Robert, 2011, Operating leverage, Review of Finance 15, 103-134.

Novy-Marx, Robert, 2013, The other side of value: The gross profitability premium, Journal of Financial Economics 108, 1-28.

Oberfield, Ezra, and Devesh Raval, 2014, Micro data and macro technology, working paper .

Papanikolaou, Dimitris, 2011, Investment shocks and asset prices, Journal of Political Economy 119, 639-685.

Peterson, Mitchell A, 1994, Cash flow variability and firm's pension choice: A role for operating leverage, Journal of Financial Economics 36, 361-383.

Petrosky-Nadeau, Nicolas, Lu Zhang, and Lars-Alexander Kuehn, 2013, Endogenous disasters and asset prices, working paper.

Piketty, Thomas, 2014, Capital in the Twenty-First Century (Belknap Press).

Santos, Tano, and Pietro Veronesi, 2006, Labor Income and Predictable Stock Returns, Review of Financial Studies 19, 1-44.

Schmidt, Lawrence, 2014, Climbing and Falling Off the Ladder: Asset Pricing Implications of Labor Market Event Risk, working paper .

Zhang, Lu, 2005, The value premium, Journal of Finance 60, 67-103.

Zhang, Mindy, 2014, Who bears firm risk? implications for cash flow volatility, working paper. 


\section{Appendix}

\section{Derivation of Labor Leverage}

Without fixed operating costs, the relative response of operating profit growth and value added growth to shocks is given by

$$
\frac{d \Delta \pi_{\mathrm{t}} / d \Delta x_{\mathrm{t}}}{d \Delta y_{\mathrm{t}} / d \Delta x_{\mathrm{t}}}=\frac{1+\frac{S_{\mathrm{t}}}{1-S_{\mathrm{t}}}\left(1-\frac{\partial \Delta w_{\mathrm{t}}}{\partial \Delta x_{\mathrm{t}}}\right)}{1+\gamma \frac{S_{\mathrm{t}}}{1-S_{\mathrm{t}}}\left(1-\frac{\partial \Delta w_{\mathrm{t}}}{\partial \Delta x_{\mathrm{t}}}\right)},
$$

where $\gamma \equiv \frac{F_{\mathrm{K}}[K, L] F_{\mathrm{L}}[K, L]}{F[K, L] F_{\mathrm{KL}}[K, L]}$ is the elasticity of substitution between labor and capital, and $S \equiv L W / Y$ is labor share. The expression follows from the following equalities:

$$
\begin{aligned}
d \Delta l_{\mathrm{t}} / d \Delta x_{\mathrm{t}} & =\frac{\gamma}{1-S_{\mathrm{t}}}\left(1-\frac{\partial \Delta w_{\mathrm{t}}}{\partial \Delta x_{\mathrm{t}}}\right), \\
d \Delta y_{\mathrm{t}} / d \Delta x_{\mathrm{t}} & =1+\gamma \frac{S_{\mathrm{t}}}{1-S_{\mathrm{t}}}\left(1-\frac{\partial \Delta w_{\mathrm{t}}}{\partial \Delta x_{\mathrm{t}}}\right), \quad \text { and } \\
d \Delta \pi_{\mathrm{t}} / d \Delta x_{\mathrm{t}} & =\frac{1}{1-S_{\mathrm{t}}}\left(1-S_{\mathrm{t}} \frac{\partial \Delta w_{\mathrm{t}}}{\partial \Delta x_{\mathrm{t}}}\right) .
\end{aligned}
$$

Operating Leverage, Labor Leverage, and Traditional Operating Leverage

Now, assume that fixed operating costs are given by $f K$, so that optimized operating profits are now given by

$$
\Pi_{\mathrm{t}}^{\mathrm{f}}=\max _{L_{\mathrm{t}}}\left\{X_{\mathrm{t}} F\left[K, L_{\mathrm{t}}\right]-L_{\mathrm{t}} W_{\mathrm{t}}-f K\right\}
$$

where the superscript $f$ in $\Pi^{\mathrm{f}}$ denotes operating profits when under fixed operating costs. Note that we can define the share of fixed costs to cash-flows net of labor costs, $S^{\mathrm{f}} \equiv \frac{f K}{Y(1-S)}$, so that

$$
\begin{aligned}
\Pi_{\mathrm{t}}^{\mathrm{f}} & =Y_{\mathrm{t}}\left(1-S_{\mathrm{t}}\right)\left(1-S_{\mathrm{t}}^{\mathrm{f}}\right) \\
& =\Pi_{\mathrm{t}}\left(1-S_{\mathrm{t}}^{\mathrm{f}}\right),
\end{aligned}
$$

where $\Pi$ are operating profits in the otherwise identical case without fixed costs. Overall operating 
leverage includes components from labor leverage and from "traditional" operating leverage as given by

$$
\begin{aligned}
1+\text { Operating Leverage } & =\frac{d \Delta \pi_{\mathrm{t}} / d \Delta x_{\mathrm{t}}}{d \Delta y_{\mathrm{t}} / d \Delta x_{\mathrm{t}}}, \\
& =\frac{d \Delta \pi_{\mathrm{t}} / d \Delta x_{\mathrm{t}}\left(1+\frac{1}{1-S_{\mathrm{t}}^{\mathrm{f}}}\right)}{d \Delta y_{\mathrm{t}} / d \Delta x_{\mathrm{t}}}, \\
& =\underbrace{\frac{1+\frac{S_{\mathrm{t}}}{1-S_{\mathrm{t}}}\left(1-\frac{\partial \Delta w_{\mathrm{t}}}{\partial \Delta x_{\mathrm{t}}}\right)}{1+\gamma_{\frac{\mathrm{t}}{\mathrm{t}}}^{1-S_{\mathrm{t}}}\left(1-\frac{\partial \Delta w_{\mathrm{t}}}{\partial \Delta \mathrm{t}_{\mathrm{t}}}\right)}}_{\text {Labor Lev. }} \underbrace{\left(1+\frac{1}{\left.1-\frac{f K}{\Pi_{\mathrm{t}}}\right)}\right.}_{\text {"Traditional" Op. Lev. }} .
\end{aligned}
$$

Expression (28c) shows how labor leverage and traditional leverage interact and magnify each other. 


\section{Proof of proposition 1}

\section{Solution to the value of the firm}

We start with the standard PDE for the value of the firm implied by the condition that the discounted value of the gains portfolio that reinvests the firm's dividends is a martingale. The solution to the value of a firm can be expressed as a function of its TFP $X$ and its labor share $S$, $V\left[X_{\mathrm{t}}, S_{\mathrm{t}}\right]$. Given that operating profits (Equation (17)) are homogeneous of degree one in $X$ and $S$, we conjecture and later verify that the value of the firm is also homogeneous of degree one in $X$ and $S$. That is, we assume the existence of a function $v[S]$ such that $V[X, S]=X K v[S]$. The homogeneity of the value of the firm allows us to simplify the PDE into the following ordinary differential equation (ODE):

$$
h\left[S_{\mathrm{t}}\right]-c_{0} v\left[S_{\mathrm{t}}\right]+c_{1} S v^{\prime}\left[S_{\mathrm{t}}\right]+c_{2} S^{2} v^{\prime \prime}\left[S_{\mathrm{t}}\right]=0,
$$

where:

$$
\begin{aligned}
h\left[S_{\mathrm{t}}\right] & \equiv \frac{\Pi_{\mathrm{t}}}{X_{\mathrm{t}} K}= \begin{cases}(1-\alpha)^{\frac{1}{\rho}}\left(1-S_{\mathrm{t}}\right)^{1-\frac{1}{\rho}}, & \text { if } \quad S_{\mathrm{t}}<1, \\
0, & \text { if } \quad S_{\mathrm{t}} \geq 1,\end{cases} \\
c_{0} & \equiv r-\lambda+\eta \rho_{\mathrm{X}} \sigma_{\mathrm{X}}-\mu_{\mathrm{X}}, \\
c_{1} & \equiv \frac{\rho\left(2 \eta \rho\left(\rho_{\mathrm{X}} \sigma_{\mathrm{X}}-\rho_{\mathrm{W}} \sigma_{\mathrm{W}}\right)+2 \eta \rho_{\mathrm{W}} \sigma_{\mathrm{W}}-2 \eta \rho_{\mathrm{X}} \sigma_{\mathrm{X}}-2 \mu_{\mathrm{W}}(1-\rho)+2 \mu_{\mathrm{X}}(1-\rho)-2 \rho_{\mathrm{W}} \rho_{\mathrm{X}} \sigma_{\mathrm{W}} \sigma_{\mathrm{X}}+\sigma_{\mathrm{W}}^{2}+\sigma_{\mathrm{X}}^{2}\right)}{2(1-\rho)^{2}}, \\
c_{2} & \equiv \frac{\rho^{2}\left(\sigma_{\mathrm{W}}^{2}+\sigma_{\mathrm{X}}^{2}-2 \rho_{\mathrm{W}} \rho_{\mathrm{X}} \sigma_{\mathrm{W}} \sigma_{\mathrm{X}}\right)}{2(1-\rho)^{2}} .
\end{aligned}
$$

The value of the firm as $S \rightarrow 0$ converges to the value of a firm with a dividend of $X_{\mathrm{t}} K(1-\alpha)^{\frac{1}{\rho}}$, a growth rate of $\mu_{x}$, and a discount rate of $r+\eta \rho_{X} \sigma_{X}$, which results in $\lim _{S \rightarrow 0} v[S]=\frac{(1-\alpha)^{\frac{1}{\rho}}}{c_{0}}$. There are three other boundary conditions. The first one corresponds to $\lim _{s \rightarrow \infty} v[S]=0$, since the value of a firm that further deviates from the region where it produces positive operating profits (i.e., its its "active region") should approach 0. The other two conditions are the smooth-pasting conditions when $S=1$ ("active-inactive threshold"). At this point $\lim _{S \rightarrow 1^{-}} v[S]=\lim _{S \rightarrow 1^{+}} v[S]$ and $\lim _{S \rightarrow 1^{-}} v^{\prime}[S]=\lim _{S \rightarrow 1^{+}} v^{\prime}[S]$.

The solution to Equation (29) in each of the two regions, active $S<1$ and inactive $S \geq 1$, has 
the general form:

$$
v[S]=v_{h}[S]+v_{p}[S]
$$

where $v_{h}[S]$ and $v_{p}[S]$ are the homogeneous and particular solutions to ODE (29).

We start by finding two linearly independent solutions to the corresponding homogeneous differential equation:

$$
v_{h}[S]=C_{1} S^{x_{1}}+C_{2} S^{x_{2}}
$$

where $x_{1}$ and $x_{2}$ are given by:

$$
\begin{aligned}
& x_{1}=\frac{c_{2}-c_{1}+\sqrt{\left(c_{2}-c_{1}\right)^{2}+4 c_{0} c_{2}}}{2 c_{2}}, \\
& x_{2}=\frac{c_{2}-c_{1}-\sqrt{\left(c_{2}-c_{1}\right)^{2}+4 c_{0} c_{2}}}{2 c_{2}} .
\end{aligned}
$$

Since, by assumption, $c_{0} c_{2}>0$, it follows that $x_{1}>0>x_{2}$. This observation will be used below.

We are looking for a particular solution of the following type:

$$
v_{p}[S]=g_{1}[S] S^{x_{1}}+g_{2}[S] S^{x_{2}}
$$

Without loss of generality, assume $g_{1}^{\prime}[S] S^{x_{1}}+g_{2}^{\prime}[S] S^{x_{2}}=0$, then substitute the particular solution into the ODE. Thus, we obtain the following system of equations:

$$
\begin{aligned}
g_{1}^{\prime}[S] S^{x_{1}}+g_{2}^{\prime}[S] S^{x_{2}} & =0 \\
g_{1}^{\prime}[S] x_{1} S^{x_{1}-1}+g_{2}^{\prime}[S] x_{2} S^{x_{2}-1} & =\frac{(1-\alpha)^{\frac{1}{\rho}}\left(1-(1-S)^{1-\frac{1}{\rho}}\right)}{c_{2} S^{2}} .
\end{aligned}
$$


Solving for $g_{1}^{\prime}[S]$ and $g_{2}^{\prime}[S]$ we find:

$$
\begin{aligned}
& g_{1}^{\prime}[S]=\frac{(1-\alpha)^{\frac{1}{\rho}}\left(1-(1-S)^{1-\frac{1}{\rho}}\right) S^{-1-x_{1}}}{c_{2}\left(x_{1}-x_{2}\right)}, \\
& g_{2}^{\prime}[S]=-\frac{(1-\alpha)^{\frac{1}{\rho}}\left(1-(1-S)^{1-\frac{1}{\rho}}\right) S^{-1-x_{2}}}{c_{2}\left(x_{1}-x_{2}\right)} .
\end{aligned}
$$

Therefore, the solution to the particular equation therefore is:

$$
v_{p}[S]=\frac{(1-\alpha)^{\frac{1}{\rho}}}{x_{1}-x_{2}}\left(S^{x_{1}} \int_{k_{1}}^{S}\left(1-(1-\tau)^{\frac{\rho-1}{\rho}}\right) \tau^{1-x_{1}} d \tau-S^{x_{2}} \int_{k_{2}}^{S}\left(1-(1-\tau)^{\frac{\rho-1}{\rho}}\right) \tau^{1-x_{2}} d \tau\right)
$$

for arbitrary constants $k_{1}$ and $k_{2}$. What remains is a choice of $k_{1}$ and $k_{2}$ so that the solution is well defined and the boundary conditions are satisfied. An easy choice is to take $k_{1}=1$ and $k_{2}=0$, then the particular solution is

$$
v_{p}[S]=\frac{(1-\alpha)^{\frac{1}{\rho}}}{x_{1}-x_{2}}\left(-S^{x_{1}} \int_{S}^{1}\left(1-(1-\tau)^{\frac{\rho-1}{\rho}}\right) \tau^{1-x_{1}} d \tau-S^{x_{2}} \int_{0}^{S}\left(1-(1-\tau)^{\frac{\rho-1}{\rho}}\right) \tau^{1-x_{2}} d \tau\right) .
$$

The general solution will be the sum of the homogeneous solution and the particular solution. Since the value of the homogeneous solution can not grow without bound as $S \rightarrow 0$ or as $S \rightarrow \infty$ the constants in the homogeneous solution associated with $S^{x_{2}}$ in the active region $S<1$ and $S^{x_{1}}$ in the inactive region $S \geq 1$ must be zero. Thus, the solution in the active region $S<1$ is:

$$
\begin{aligned}
& v[S]=D_{1} S^{x_{1}}- \\
& \quad \frac{2(1-\alpha)^{\frac{1}{\rho}}}{\sigma_{S}^{2}\left(x_{1}-x_{2}\right)}\left(S^{x_{1}} \int_{S}^{1}\left(1-(1-\tau)^{\frac{\rho-1}{\rho}}\right) \tau^{-1-x_{1}} d \tau+S^{x_{2}} \int_{0}^{S}\left(1-(1-\tau)^{\frac{\rho-1}{\rho}}\right) \tau^{-1-x_{2}} d \tau\right),
\end{aligned}
$$

and the solution in the inactive region $S \geq 1$ is

$$
v[S]=D_{2} S^{x_{2}} .
$$

What remains is to find the constants $D_{1}$ and $D_{2}$ such that the smooth-pasting conditions hold. The limit of $v_{p}[S]$ as $S \rightarrow 0$ is 0 , so meeting the boundary condition for $S=0$ will come from the solution to the homogeneous differential equation. 
Define $A_{2} \equiv \int_{0}^{1}\left(1-(1-\tau)^{\frac{\rho-1}{\rho}}\right) \tau^{-1-x_{2}} d \tau$. It is easy to see that $v_{p}[1]=\frac{-2(1-\alpha)^{\frac{1}{\rho}} A_{2}}{2 c_{2}\left(x_{1}-x_{2}\right)}$ and $v_{p}^{\prime}[1]=$ $\frac{-2(1-\alpha)^{\frac{1}{\rho}} x_{2} A_{2}}{2 c_{2}\left(x_{1}-x_{2}\right)}$. Thus from the smooth-pasting conditions we obtain

$$
\begin{aligned}
\frac{-2(1-\alpha)^{\frac{1}{\rho}} A_{2}}{2 c_{2}\left(x_{1}-x_{2}\right)}+D_{1}+\frac{(1-\alpha)^{\frac{1}{\rho}}}{c_{0}} & =D_{2} \\
\frac{-2(1-\alpha)^{\frac{1}{\rho}} x_{2} A_{2}}{2 c_{2}\left(x_{1}-x_{2}\right)}+D_{1} x_{1} & =D_{2} x_{2} .
\end{aligned}
$$

Solving for $D_{1}$ and $D_{2}$,

$$
\begin{aligned}
& D_{1}=\frac{\frac{(1-\alpha)^{\frac{1}{\rho}}}{c_{0}} x_{2}}{x_{1}-x_{2}} \\
& D_{2}=\frac{(1-\alpha)^{\frac{1}{\rho}}}{2 c_{2}\left(x_{1}-x_{2}\right)}\left(-2 A_{2}+\frac{2 c_{2} x_{1}}{c_{0}}\right) .
\end{aligned}
$$

The complete solution to the value of the firm is, therefore

In the active region $S<1$ :

$$
\begin{aligned}
& v[S]=\frac{2(1-\alpha)^{\frac{1}{\rho}}}{2 c_{2} c_{0}\left(x_{1}-x_{2}\right)}\left(\left(x_{1}-x_{2}\right) \frac{2 c_{2}}{2}+\frac{2 c_{2}}{2} x_{2} S^{x_{1}}-\right. \\
& \left.\quad c_{0} S^{x_{1}} \int_{S}^{1}\left(1-(1-\tau)^{\frac{\rho-1}{\rho}}\right) \tau^{1-x_{1}} d \tau-c_{0} S^{x_{2}} \int_{0}^{S}\left(1-(1-\tau)^{\frac{\rho-1}{\rho}}\right) \tau^{1-x_{2}} d \tau\right) .
\end{aligned}
$$

In the inactive region $S \geq 1$ :

$$
v[S]=\frac{2(1-\alpha)^{\frac{1}{\rho}}}{2 c_{2} c_{0}\left(x_{1}-x_{2}\right)}\left(-A_{2} c_{0}+\frac{2 c_{2} x_{1}}{2}\right) S^{x_{2}}
$$




\section{Table I \\ Summary Statistics}

Panels A and B report time series averages of median characteristics of portfolios of firms sorted on labor share (LS) and the extended measure of labor share (ELS), respectively. $L S$ is ratio of labor expenses over the sum of labor expenses, operating profits, and the change in inventories of final goods. The construction of $E L S$ is identical to that of $L S$, except that, for firms that do not report labor expenses, we proxy them by the product of the number of employees in the firm and the average wage in the industry. $L o g$. $L / K$ is the logarithm of the ratio of the number of employees over PPE. $B / M$ is the shareholders' book value of equity divided by the market value of equity. Log Size is the logarithm of market value of equity. Log. Asset is the logarithm of the book value of assets. Tang. is tangibility, and is defined as the ratio of plant, property, and equipment (PPE) over assets. Org. Cap is organizational capital, constructed as in Eisfeldt and Papanikolaou (2013). Lev. is leverage, and is defined as the ratio of the book value of debt minus cash and marketable securities over the book value of assets minus cash and marketable securities. Prof. is the measure of gross profitability as defined by Novy-Marx (2013). All variables are adjusted for inflation as measured by the Consumer Price Index. The sample covers all industries in Compustat, except Financials, over the period 1963-2012.

\begin{tabular}{|c|c|c|c|c|c|c|c|c|c|c|c|}
\hline Col. & 1 & 2 & 3 & 4 & 5 & 6 & 7 & 8 & 9 & 10 & 11 \\
\hline & LS & ELS & $\begin{array}{l}\text { Log. } \\
\text { L/K }\end{array}$ & $\mathrm{B} / \mathrm{M}$ & $\begin{array}{l}\text { Log. } \\
\text { Size }\end{array}$ & $\begin{array}{l}\text { Log. } \\
\text { Asset }\end{array}$ & Tang. & $\begin{array}{l}\text { Org. } \\
\text { Cap. }\end{array}$ & Lev. & Prof. & $\begin{array}{l}\text { Obs/ } \\
\text { Year }\end{array}$ \\
\hline \multicolumn{12}{|c|}{ Panel A: LS-Quintile Portfolios (Sample With Non-Missing LS) } \\
\hline All & 0.62 & 0.62 & 2.47 & 0.68 & 7.18 & 7.56 & 0.50 & 0.98 & 0.54 & 0.24 & 285 \\
\hline $\mathrm{L}$ & 0.33 & 0.33 & 0.52 & 0.72 & 7.73 & 8.19 & 0.71 & 0.51 & 0.62 & 0.16 & 57 \\
\hline 2 & 0.47 & 0.47 & 1.32 & 0.67 & 7.45 & 7.86 & 0.62 & 0.84 & 0.58 & 0.20 & 57 \\
\hline 3 & 0.62 & 0.62 & 2.69 & 0.57 & 7.47 & 7.47 & 0.45 & 1.02 & 0.47 & 0.33 & 57 \\
\hline 4 & 0.72 & 0.72 & 3.10 & 0.69 & 7.01 & 7.26 & 0.43 & 1.06 & 0.49 & 0.30 & 57 \\
\hline $\mathrm{H}$ & 0.83 & 0.83 & 3.49 & 0.83 & 6.39 & 7.02 & 0.35 & 1.07 & 0.56 & 0.23 & 57 \\
\hline \multicolumn{12}{|c|}{ Panel B: ELS-Quintile Portfolios (Sample With Non-Missing ELS) } \\
\hline All & 0.62 & 0.65 & 3.01 & 0.62 & 6.48 & 6.69 & 0.31 & 1.23 & 0.50 & 0.34 & 1632 \\
\hline $\mathrm{L}$ & 0.33 & 0.32 & 0.81 & 0.63 & 7.22 & 7.43 & 0.59 & 0.63 & 0.58 & 0.21 & 326 \\
\hline 2 & 0.53 & 0.53 & 2.60 & 0.49 & 6.89 & 6.83 & 0.32 & 1.17 & 0.47 & 0.39 & 327 \\
\hline 3 & 0.65 & 0.65 & 3.09 & 0.57 & 6.56 & 6.64 & 0.30 & 1.28 & 0.47 & 0.40 & 327 \\
\hline 4 & 0.74 & 0.74 & 3.31 & 0.69 & 6.22 & 6.53 & 0.28 & 1.37 & 0.49 & 0.37 & 327 \\
\hline $\mathrm{H}$ & 0.85 & 0.85 & 3.63 & 0.82 & 5.74 & 6.28 & 0.27 & 1.43 & 0.52 & 0.33 & 326 \\
\hline
\end{tabular}




\section{Table II}

\section{Smoothness and Cyclicality of Aggregate Wages and Aggregate Profits}

This table reports estimates and standard errors of time-series regressions of measures of aggregate profit growth on aggregate GDP, TFP, and wage growth. $g d p^{g}$ is annualized growth calculated as the change of the logarithm of real GDP. $t f p^{g}$ is annualized growth calculated as the change of the logarithm of TFP. wage $e^{g}$ is annualized growth calculated as the change of the logarithm of real wages. profit $t^{g}$ is annualized growth in corporate profits from the National Income and Product Accounts. Standard errors clustered by year are shown in parentheses. The sample covers the period 1963-2012.

\begin{tabular}{|c|c|c|c|c|}
\hline Variable & $\operatorname{gdp}^{\mathrm{g}}$ & $\mathrm{tfp}^{\mathrm{g}}$ & wage $^{\mathrm{g}}$ & profit $^{\mathrm{g}}$ \\
\hline $\operatorname{gdp} p^{g}$ & 1.000 & & & \\
\hline $\mathrm{tfp}^{\mathrm{g}}$ & 0.862 & 1.000 & & \\
\hline wage $^{g}$ & 0.275 & 0.480 & 1.000 & \\
\hline profit $^{\mathrm{g}}$ & 0.628 & 0.621 & -0.063 & 1.000 \\
\hline$\sigma$ & 0.030 & 0.017 & 0.015 & 0.105 \\
\hline$\sigma / \sigma^{\mathrm{gdp}}$ & 1.000 & 0.573 & 0.513 & 3.538 \\
\hline Slope on $\mathrm{gdp}^{\mathrm{g} *}$ & 1.000 & 0.494 & 0.141 & 2.222 \\
\hline
\end{tabular}


Table III

\section{Smoothness of Labor Costs}

This table reports estimates of panel data regressions of changes of costs on changes in sales. $\Delta \mathrm{lc}$ and $\mathrm{lc}^{\mathrm{g}}(\%)$ are the $\$$ and $\%$ changes of staff expenses. $\Delta$ nlc and nlc ${ }^{\mathrm{g}}(\%)$ are the $\$$ and $\%$ changes of the sum of operating expenses (SG\&A and COGS) minus staff expenses. $\Delta$ tc and $\mathrm{tc}^{\mathrm{g}}(\%)$ are the $\$$ and $\%$ changes of the sum of operating expenses (SG\&A and COGS). Standard errors clustered by firm are shown in parentheses. Significance levels are denoted by $(*=10 \%$ level $),(* *=5 \%$ level $)$, and $(* * *=1 \%$ level $)$. The sample covers all industries in Compustat, except Financials, over the period 1963-2012.

\begin{tabular}{|c|c|c|c|c|c|c|}
\hline & \multicolumn{6}{|c|}{ Cost (Dependent Variable) } \\
\hline & $\Delta \mathrm{lc}$ & $\Delta \mathrm{nlc}$ & $\Delta \mathrm{tc}$ & $1 c^{g}(\%)$ & $\operatorname{nlc}^{\mathrm{g}}(\%)$ & $\mathrm{tc}^{\mathrm{g}}(\%)$ \\
\hline$\Delta$ sale & $\begin{array}{l}0.09^{* * *} \\
(0.01)\end{array}$ & $\begin{array}{l}0.72^{\text {*** }} \\
(0.03)\end{array}$ & $\begin{array}{l}0.81^{* * *} \\
(0.03)\end{array}$ & & & \\
\hline $\operatorname{sale}^{\mathrm{g}}(\%)$ & & & & $\begin{array}{c}0.43^{* * *} \\
(0.16)\end{array}$ & $\begin{array}{l}1.46^{* * *} \\
(0.28)\end{array}$ & $\begin{array}{l}1.07^{* * *} \\
(0.12)\end{array}$ \\
\hline Firm FE & $\mathrm{Y}$ & $\mathrm{Y}$ & $\mathrm{Y}$ & $\mathrm{Y}$ & $\mathrm{Y}$ & $\mathrm{Y}$ \\
\hline R-sq. (\%) & 19.23 & 72.88 & 76.69 & 0.00 & 9.96 & 59.25 \\
\hline Obs. & 8,173 & 8,173 & 8,173 & 8,173 & 8,173 & 8,173 \\
\hline
\end{tabular}




\section{Table IV \\ Cyclicality of Labor Share}

This table reports estimates and standard errors of panel data regressions of firm-level measures of labor share (LS and ELS) on growth in business cycle indicators. $g d p^{g}$ is annualized growth calculated as the change of the logarithm of real GDP. $t f p^{\mathrm{g}}$ is annualized growth calculated as the change of the logarithm of TFP. $m k t^{g}$ is the annualized excess return of the market factor described in Fama and French (1993) and obtained from Kenneth French's website. Standard errors clustered by year are shown in parentheses. Significance levels are denoted by $(*=10 \%$ level $),(* *=5 \%$ level $)$, and $(* * *=1 \%$ level). The sample covers all industries in Compustat, except Financials, over the period 1963-2012.

\begin{tabular}{|c|c|c|c|c|c|c|}
\hline \multirow[b]{3}{*}{ Shock } & \multicolumn{6}{|c|}{ Proxy for Labor Share (S) } \\
\hline & \multicolumn{3}{|c|}{ LS } & \multicolumn{3}{|c|}{ ELS } \\
\hline & I & II & III & I & II & III \\
\hline $\operatorname{gdp}_{t}^{\mathrm{g}}$ & $\begin{array}{c}-0.33^{* * *} \\
(0.12)\end{array}$ & & & $\begin{array}{c}-0.46^{* * *} \\
(0.10)\end{array}$ & & \\
\hline $\mathrm{tfp}_{t}^{\mathrm{g}}$ & & $\begin{array}{l}-0.43^{*} \\
(0.25)\end{array}$ & & & $\begin{array}{c}-0.52^{* *} \\
(0.23)\end{array}$ & \\
\hline$m k t_{t}^{\mathrm{g}}$ & & & $\begin{array}{l}-0.03^{*} \\
(0.02)\end{array}$ & & & $\begin{array}{c}-0.06^{* * *} \\
(0.02)\end{array}$ \\
\hline Firm FE & $\mathrm{Y}$ & Y & $\mathrm{Y}$ & Y & $\mathrm{Y}$ & $\mathrm{Y}$ \\
\hline R-sq. (\%) & 0.54 & 0.30 & 0.16 & 0.34 & 0.14 & 0.25 \\
\hline Obs. & 13,508 & 13,508 & 13,508 & 75,720 & 75,720 & 75,720 \\
\hline
\end{tabular}




\section{Table V}

\section{Elasticity of Substitution Between Labor and Capital}

This table presents estimates of the elasticity of substitution between labor and capital. We proceed in two stages. In the first stage, we estimate the elasticity to shocks of operating profit growth $\left(\Theta^{\Pi}\right)$ and value added growth $\left(\Theta^{\mathrm{Y}}\right)$. The table shows estimates of time-series regressions of firm-level measures of real operating profit $\Pi$ growth and real value added $Y$ growth on aggregate GDP growth, TFP growth, and the returns on the market portfolio. In the second stage, we regress $\hat{\Theta}^{\Pi}$ on $\hat{\Theta}^{\mathrm{Y}}$ from the first pass to obtain estimates of the elasticity of substitution between labor and capital. A value added is constructed as the sum of labor expenses, operating profits before interest and depreciation, adjusted for changes in the inventories of final goods. In Panel A, the labor expenses used are staff expenses (XLR), and in Panel B, the product of the number of employees (EMP) and the industry average of (XLR/EMP) is used if XLR is missing. $g d p^{g}$ is annualized growth calculated as the change of the logarithm of real GDP. $t f p^{\mathrm{g}}$ is annualized growth calculated as the change of the logarithm of TFP. $M K T$ is the excess market return factor from Kenneth French's website. Standard errors clustered by firm are shown in parentheses. Significance levels are denoted by $(*=$ $10 \%$ level), $(* *=5 \%$ level), and $(* * *=1 \%$ level). The sample covers all industries in Compustat, except Financials, over the period 1963-2012.

\begin{tabular}{|c|c|c|c|c|c|c|c|c|c|}
\hline & \multicolumn{6}{|c|}{ First Stage } & \multirow{2}{*}{\multicolumn{3}{|c|}{$\begin{array}{c}\text { Second Stage } \\
\text { L/K Elasticity of Subs. }\end{array}$}} \\
\hline & \multicolumn{3}{|c|}{$\hat{\Theta}^{\Pi}$} & \multicolumn{3}{|c|}{$\hat{\Theta}^{Y}$} & & & \\
\hline & I & II & III & I & II & III & I & II & III \\
\hline \multicolumn{10}{|c|}{ Panel A: Sample with Non-Missing XLR-Based Value Added } \\
\hline $\operatorname{gdp}_{t}^{\mathrm{g}}$ & $\begin{array}{l}5.66^{* * *} \\
(0.25)\end{array}$ & & & $\begin{array}{l}3_{3.21^{* * *}}^{* *} \\
(0.12)\end{array}$ & & & $\begin{array}{c}0.40^{* * *} \\
(0.03)\end{array}$ & & \\
\hline $\operatorname{tfp}_{t}^{g}$ & & $\begin{array}{l}10.19^{* * *} \\
(0.44)\end{array}$ & & & $\begin{array}{l}5.68^{* * *} \\
(0.21)\end{array}$ & & & $\begin{array}{c}0.40^{* * *} \\
(0.03)\end{array}$ & \\
\hline $\mathrm{MKT}_{t}$ & & & $\begin{array}{l}0.79^{* * *} \\
(0.04)\end{array}$ & & & $\begin{array}{l}0.47^{* * *} \\
(0.02)\end{array}$ & & & $\begin{array}{l}0.40^{* * *} \\
(0.03)\end{array}$ \\
\hline R-sq. (\%) & 0.13 & 0.11 & 0.04 & 0.15 & 0.13 & 0.04 & 0.67 & 0.70 & 0.62 \\
\hline Obs. & 10,536 & 10,536 & 10,536 & 10,536 & 10,536 & 10,536 & 10,536 & 10,536 & 10,536 \\
\hline \multicolumn{10}{|c|}{ Panel B: Full Sample } \\
\hline $\operatorname{gdp}_{t}^{\mathrm{g}}$ & $\begin{array}{l}9.29^{* * *} \\
(0.17)\end{array}$ & & & $\begin{array}{l}7.55^{* * *} \\
(0.15)\end{array}$ & & & $\begin{array}{c}0.57^{* * *} \\
(0.02)\end{array}$ & & \\
\hline $\operatorname{tfp}_{t}^{\mathrm{g}}$ & & $\begin{array}{l}16.01^{* * *} \\
(0.30)\end{array}$ & & & $\begin{array}{l}12.50^{* * *} \\
(0.23)\end{array}$ & & & $\begin{array}{l}0.54^{* * *} \\
(0.02)\end{array}$ & \\
\hline $\mathrm{MKT}_{t}$ & & & $\begin{array}{l}1.18^{* * *} \\
(0.02)\end{array}$ & & & $\begin{array}{l}0.85^{* * *} \\
(0.01)\end{array}$ & & & $\begin{array}{l}0.42^{* * *} \\
(0.02)\end{array}$ \\
\hline R-sq. (\%) & 0.09 & 0.07 & 0.04 & 0.07 & 0.05 & 0.03 & 0.43 & 0.47 & 0.44 \\
\hline Obs. & 54,406 & 54,406 & 54,406 & 54,406 & 54,406 & 54,406 & 54,406 & 54,406 & 54,406 \\
\hline
\end{tabular}




\section{Table VI \\ Labor Share and Sensitivity of Operating Profits to Macroeconomic Shocks}

This table reports estimates and standard errors of panel data regressions of measures of real operating income before depreciation growth $\left(\mathrm{OP}^{\mathrm{g}}\right)$ on aggregate GDP, TFP, wage growth, standardized labor share, and interaction terms. $g d p^{g}$ is annualized growth calculated as the change of the logarithm of real GDP. $t f p^{\mathrm{g}}$ is annualized growth calculated as the change of the logarithm of TFP. $m k t^{\mathrm{g}}$ is the annualized excess return of the market factor described in Fama and French (1993) and obtained from Kenneth French's website. $L S$ and $E L S$ are standardized every year. Standard errors clustered by year are shown in parentheses. Significance levels are denoted by $(*=10 \%$ level $),(* *=5 \%$ level $)$, and $(* * *$ $=1 \%$ level). The sample covers all industries in Compustat, except Financials, over the period 19632012.

\begin{tabular}{|c|c|c|c|c|c|c|}
\hline & \multicolumn{3}{|c|}{$\mathrm{LS}$} & \multicolumn{3}{|c|}{ ELS } \\
\hline & \multicolumn{3}{|c|}{ Aggregate Shock } & \multicolumn{3}{|c|}{ Aggregate Shock } \\
\hline & $g d p^{\mathrm{g}}$ & $t f p^{\mathrm{g}}$ & $m k t^{\mathrm{g}}$ & $g d p^{g}$ & $t f p^{\mathrm{g}}$ & $m k t^{\mathrm{g}}$ \\
\hline \multirow{2}{*}{$\operatorname{shock}_{t}$} & $1.96^{* * *}$ & $2.83^{* * *}$ & $0.18^{* * *}$ & $2.37^{* * *}$ & $2.79^{* * *}$ & $0.28^{* * *}$ \\
\hline & $(0.23)$ & $(0.59)$ & $(0.05)$ & $(0.26)$ & $(0.67)$ & $(0.06)$ \\
\hline \multirow[t]{2}{*}{$\mathrm{S}_{i t-1} \times \operatorname{shock}_{t}$} & $1.15^{* * *}$ & $1.53^{* * *}$ & $0.12^{* * *}$ & $0.54^{* * *}$ & $0.90^{* * *}$ & $0.06^{*}$ \\
\hline & $(0.21)$ & $(0.45)$ & $(0.04)$ & $(0.26)$ & $(0.03)$ & \\
\hline \multirow[t]{2}{*}{$\mathrm{S}_{i t-1}$} & $0.13^{* * *}$ & $0.14^{* * *}$ & $0.16^{* * *}$ & $0.16^{* * *}$ & $0.16^{* * *}$ & $0.18^{* * *}$ \\
\hline & $(0.01)$ & $(0.02)$ & $(0.02)$ & $(0.01)$ & $(0.01)$ & $(0.01)$ \\
\hline Firm FE & $\mathrm{Y}$ & Y & $\mathrm{Y}$ & $\mathrm{Y}$ & Y & Y \\
\hline R-sq. (\%) & 10.89 & 9.11 & 6.80 & 8.59 & 6.98 & 7.21 \\
\hline Obs. & 13,530 & 13,530 & 13,530 & 68,873 & 68,873 & 68,873 \\
\hline
\end{tabular}




\section{Table VII}

\section{Average Stock Returns of Firms Sorted on Labor Share}

This table reports two-years ahead post-ranking mean annual excess stock returns over annualized one-month Treasury bill rates of equal- and value-weighted portfolios of firms sorted on twice-lagged LS and ELS. H-L is the zero net investment portfolio long high labor share $(\mathrm{H})$ stocks and short low labor share (L) stocks. Newey-West standard errors estimated with five lags are shown in parentheses. The sample covers all industries in Compustat, except Financials, over the period 1964-2012.

\begin{tabular}{lcccccc}
\hline & \multicolumn{5}{c}{ Portfolio } \\
\cline { 2 - 6 } & $\mathrm{L}$ & 2 & 3 & 4 & $\mathrm{H}$ & $\mathrm{H}-\mathrm{L}$ \\
\hline \multicolumn{5}{c}{ Equally-Weighted Returns } \\
$\mathrm{LS}_{t-2}$ & $6.91^{* * *}$ & $8.94^{* * *}$ & $9.18^{* * *}$ & $8.77^{* * *}$ & $11.72^{* * *}$ & $4.82^{* *}$ \\
& $(1.88)$ & $(1.89)$ & $(2.05)$ & $(2.22)$ & $(2.70)$ & $(2.25)$ \\
ELS $_{t-2}$ & $8.49^{* * *}$ & $9.73^{* * *}$ & $10.02^{* * *}$ & $10.81^{* * *}$ & $11.78^{* * *}$ & $3.29^{*}$ \\
& $(1.95)$ & $(1.86)$ & $(2.03)$ & $(2.24)$ & $(2.72)$ & $(1.91)$ \\
& & \multicolumn{7}{c}{ Value-Weighted Returns } & & \\
LS $_{t-2}$ & $6.11^{* * *}$ & $7.80^{* * *}$ & $6.26^{* * *}$ & $5.73^{* *}$ & $10.18^{* * *}$ & $4.06^{*}$ \\
& $(1.91)$ & $(1.90)$ & $(2.01)$ & $(2.67)$ & $(2.46)$ & $(2.20)$ \\
ELS $_{t-2}$ & $6.98^{* * *}$ & $7.36^{* * *}$ & $7.00^{* * *}$ & $7.47^{* * *}$ & $10.23^{* * *}$ & $3.25^{*}$ \\
& $(1.79)$ & $(1.78)$ & $(1.74)$ & $(2.11)$ & $(2.54)$ & $(1.92)$ \\
\hline
\end{tabular}




\section{Table VIII}

\section{Stock Returns and Labor Share}

This table shows estimates and standard errors of panel data regressions of annual stock returns on twice-lagged measures of labor share and controls for leverage and assets. Standard errors clustered by firm are shown in parentheses. Significance levels are denoted by $(*=10 \%$ level), $(* *=5 \%$ level $)$, and $(* * *=1 \%$ level $)$. The sample covers all industries in Compustat, except Financials, over the period 1964-2012.

\begin{tabular}{|c|c|c|c|c|c|c|}
\hline & \multicolumn{3}{|c|}{ LS } & \multicolumn{3}{|c|}{ ELS } \\
\hline & I & II & III & I & II & III \\
\hline $\mathrm{S}_{t-2}$ & $\begin{array}{l}1.21^{\text {*** }} \\
(0.31)\end{array}$ & $\begin{array}{l}1.37^{\text {*** }} \\
(0.35)\end{array}$ & $\begin{array}{c}1.18^{* * *} \\
(0.35)\end{array}$ & $\begin{array}{l}0.82^{\text {*** }} \\
(0.20)\end{array}$ & $\begin{array}{l}0.84^{* * *} \\
(0.20)\end{array}$ & $\begin{array}{l}0.70^{* * *} \\
(0.20)\end{array}$ \\
\hline $\operatorname{Lev}_{t-2}$ & & $\begin{array}{c}4.53^{*} \\
(2.35)\end{array}$ & $\begin{array}{c}6.44^{* *} \\
(2.56)\end{array}$ & & $\begin{array}{l}4.85^{* * *} \\
(1.22)\end{array}$ & $\begin{array}{l}6.36^{* * *} \\
(1.39)\end{array}$ \\
\hline Assets $_{t-2}$ & & & $\begin{array}{l}-0.71^{* * *} \\
(0.23)\end{array}$ & & & $\begin{array}{l}-0.44^{* * *} \\
(0.13)\end{array}$ \\
\hline Year FE & Y & $Y$ & Y & Y & $Y$ & $\mathrm{Y}$ \\
\hline R-sq. (\%) & 0.10 & 0.13 & 0.21 & 0.02 & 0.05 & 0.06 \\
\hline Obs. & 14,291 & 14,291 & 14,291 & 78,719 & 78,719 & 78,719 \\
\hline
\end{tabular}




\section{Table IX \\ Risk Factor Loadings}

This table reports the average conditional betas of portfolios of stocks sorted on lagged measures of labor share (LS and ELS). MKT, SMB, and HML are the market, size, and value risk factors described in Fama and French (1993) and obtained from Kenneth French's website. $t f p^{\mathrm{g}}$, wage $e^{\mathrm{g}}$, and $g d p^{g}$ are total factor productivity, wages, and gross domestic product growth described in Table 2. H-L is the zero net investment portfolio long high labor share $(\mathrm{H})$ stocks and short low labor share (L) stocks. Newey-West standard errors estimated with one lag are shown in parentheses. Significance levels are denoted by $(*=10 \%$ level $),(* *=5 \%$ level $)$, and $(* * *=1 \%$ level $)$. The sample covers all industries in Compustat, except Financials, over the period 1964-2012.

\begin{tabular}{|c|c|c|c|c|c|c|}
\hline \multirow[b]{2}{*}{ Factor } & \multicolumn{6}{|c|}{ Portfolio } \\
\hline & $\mathrm{L}$ & 2 & 3 & 4 & $\mathrm{H}$ & $\mathrm{H}-\mathrm{L}$ \\
\hline \multicolumn{7}{|c|}{ Panel A: Average Betas of Portfolios Sorted on LS } \\
\hline MKT & $\begin{array}{l}0.69^{\text {*** }} \\
(0.09)\end{array}$ & $\begin{array}{l}0.81^{\text {*** }} \\
(0.05)\end{array}$ & $\begin{array}{l}1.08^{* * *} \\
(0.05)\end{array}$ & $\begin{array}{l}1.21^{* * *} \\
(0.04)\end{array}$ & $\begin{array}{l}1.37^{* * *} \\
(0.08)\end{array}$ & $\begin{array}{l}0.68^{* * *} \\
(0.10)\end{array}$ \\
\hline SMB & $\begin{array}{c}0.32^{*} \\
(0.17)\end{array}$ & $\begin{array}{l}0.49^{* * *} \\
(0.18)\end{array}$ & $\begin{array}{l}0.87^{* * *} \\
(0.16)\end{array}$ & $\begin{array}{l}1.03^{* * *} \\
(0.16)\end{array}$ & $\begin{array}{l}1.39^{* * *} \\
(0.16)\end{array}$ & $\begin{array}{l}1.08^{* * *} \\
(0.08)\end{array}$ \\
\hline HML & $\begin{array}{l}-0.01 \\
(0.10)\end{array}$ & $\begin{array}{l}-0.11 \\
(0.15)\end{array}$ & $\begin{array}{l}-0.32 \\
(0.20)\end{array}$ & $\begin{array}{l}-0.37^{*} \\
(0.22)\end{array}$ & $\begin{array}{l}-0.50^{*} \\
(0.26)\end{array}$ & $\begin{array}{l}-0.49^{* *} \\
(0.20)\end{array}$ \\
\hline$t f p^{\mathrm{g}}$ & $\begin{array}{c}2.21 \\
(1.79)\end{array}$ & $\begin{array}{c}2.72 \\
(2.14)\end{array}$ & $\begin{array}{l}3.44 \\
(2.14)\end{array}$ & $\begin{array}{l}4.30^{*} \\
(2.37)\end{array}$ & $\begin{array}{l}6.06^{* *} \\
(2.90)\end{array}$ & $\begin{array}{l}3.85^{\text {*** }} \\
(1.41)\end{array}$ \\
\hline$g d p^{\mathrm{g}}$ & $\begin{array}{c}0.34 \\
(1.86)\end{array}$ & $\begin{array}{c}0.34 \\
(1.69)\end{array}$ & $\begin{array}{l}1.44 \\
(2.08)\end{array}$ & $\begin{array}{l}2.11 \\
(2.11)\end{array}$ & $\begin{array}{l}4.19 \\
(2.91)\end{array}$ & $\begin{array}{l}3.86^{* *} \\
(1.62)\end{array}$ \\
\hline wage $^{g}$ & $\begin{array}{c}1.69 \\
(1.53)\end{array}$ & $\begin{array}{l}-1.67 \\
(3.56)\end{array}$ & $\begin{array}{l}4.75^{*} \\
(2.57)\end{array}$ & $\begin{array}{c}3.89 \\
(3.28)\end{array}$ & $\begin{array}{c}3.48 \\
(3.02)\end{array}$ & $\begin{array}{l}1.79 \\
(2.59)\end{array}$ \\
\hline \multicolumn{7}{|c|}{ Panel B: Average Betas of Portfolios Sorted on ELS } \\
\hline MKT & $\begin{array}{l}1.05^{\text {*** }} \\
(0.07)\end{array}$ & $\begin{array}{l}1.31^{* * *} \\
(0.05)\end{array}$ & $\begin{array}{l}1.37^{* * *} \\
(0.05)\end{array}$ & $\begin{array}{l}1.44^{* * *} \\
(0.05)\end{array}$ & $\begin{array}{l}1.52^{* * *} \\
(0.07)\end{array}$ & $\begin{array}{l}0.47^{* * *} \\
(0.07)\end{array}$ \\
\hline SMB & $\begin{array}{l}0.73^{* * *} \\
(0.13)\end{array}$ & $\begin{array}{l}1.05^{* * *} \\
(0.12)\end{array}$ & $\begin{array}{l}1.21^{* * *} \\
(0.13)\end{array}$ & $\begin{array}{l}1.32^{* * *} \\
(0.14)\end{array}$ & $\begin{array}{l}1.56^{* * *} \\
(0.13)\end{array}$ & $\begin{array}{l}0.83^{* * *} \\
(0.05)\end{array}$ \\
\hline HML & $\begin{array}{l}-0.43^{* * *} \\
(0.15)\end{array}$ & $\begin{array}{l}-0.67^{\text {*** }} \\
(0.21)\end{array}$ & $\begin{array}{l}-0.60^{* *} \\
(0.23)\end{array}$ & $\begin{array}{l}-0.57^{* *} \\
(0.23)\end{array}$ & $\begin{array}{l}-0.55^{* *} \\
(0.24)\end{array}$ & $\begin{array}{l}-0.12 \\
(0.10)\end{array}$ \\
\hline$t f p^{\mathrm{g}}$ & $\begin{array}{c}3.81 \\
(2.41)\end{array}$ & $\begin{array}{l}4.93^{*} \\
(2.44)\end{array}$ & $\begin{array}{l}5.15^{* *} \\
(2.26)\end{array}$ & $\begin{array}{l}5.38^{* *} \\
(2.39)\end{array}$ & $\begin{array}{l}5.93^{* *} \\
(2.43)\end{array}$ & $\begin{array}{l}2.12^{* *} \\
(0.80)\end{array}$ \\
\hline$g d p^{\mathrm{g}}$ & $\begin{array}{c}1.78 \\
(1.93)\end{array}$ & $\begin{array}{c}2.17 \\
(2.13)\end{array}$ & $\begin{array}{c}2.86 \\
(2.00)\end{array}$ & $\begin{array}{c}2.88 \\
(1.96)\end{array}$ & $\begin{array}{c}3.56 \\
(2.20)\end{array}$ & $\begin{array}{l}1.78^{* *} \\
(0.83)\end{array}$ \\
\hline wage $^{g}$ & $\begin{array}{c}0.84 \\
(1.82)\end{array}$ & $\begin{array}{c}0.18 \\
(3.38)\end{array}$ & $\begin{array}{l}4.02 \\
(3.19)\end{array}$ & $\begin{array}{c}3.14 \\
(2.93)\end{array}$ & $\begin{array}{c}3.66 \\
(3.36)\end{array}$ & $\begin{array}{l}2.83 \\
(2.09)\end{array}$ \\
\hline
\end{tabular}




\section{Table X \\ Target Moments in Calibration}

This table shows the target moments and the loss function weights used in the calibration of the model.

\begin{tabular}{llc}
\hline Moment & $\begin{array}{l}\text { Target } \\
\text { Moment }\end{array}$ & $\begin{array}{c}\text { LF } \\
\text { Weight }\end{array}$ \\
\hline Moments from Macroeconomic Variables & & \\
Volatility of GDP growth & 0.035 & 0.095 \\
Volatility of aggregate TFP growth & 0.020 & 0.095 \\
Volatility of aggregate wage growth & 0.018 & 0.095 \\
Correlation between GDP growth and agg. TFP growth & 0.862 & 0.048 \\
Correlation between GDP growth and agg. wage growth & 0.275 & 0.048 \\
Correlation between agg. TFP growth and agg. wage growth & 0.482 & 0.048 \\
Moments from Firm-Level Cash Flows & & \\
Mean Labor Share & 0.594 & 0.583 \\
Cross-Sectional Std. Dev. of Value-Added Growth & 0.131 & 0.048 \\
Cross-Sectional Std. Dev. of Labor Share & 0.186 & 0.048 \\
Slope of GDP growth from regression (9) & 1.960 & 0.024 \\
Slope of TFP growth from regression (9) & 2.830 & 0.024 \\
Slope of interaction LS $\times$ GDP growth from regression (9) & 1.150 & 0.024 \\
Slope of interaction LS $\times$ TFP growth from regression (9) & 1.530 & 0.024 \\
Moments from Firm-Level Unlevered Stock Returns & & \\
Return of Low-Labor-Share Quintile Portfolio & 2.830 & 0.095 \\
Return of High-Labor-Share Quintile Portfolio & 4.720 & 0.095 \\
Return of High- minus Low-Labor-Share Quintile Portfolio & 1.890 & 0.095 \\
\hline
\end{tabular}


Table XI

\section{Parameter Calibration}

This table shows the parameter values obtained in the model calibration.

\begin{tabular}{lll}
\hline Parameter & Symbol & Value \\
\hline Productive Technology & $\frac{1}{1-\rho}$ & \\
K-L elasticity of substitution & $\alpha$ & 0.400 \\
Weight of labor in productive technology & & 0.813 \\
Shocks & $\sigma_{\mathrm{W}}$ & \\
Volatility of wage shocks & $\mu_{\mathrm{W}}$ & 0.021 \\
Drift of wage shocks & $\rho_{\mathrm{W}}$ & 0.030 \\
Priced portion of wage shocks & $\sigma_{\mathrm{A}}$ & 0.535 \\
Volatility of productivity shocks & $\mu_{\mathrm{A}}$ & 0.075 \\
Drift of productivity shocks & $\rho_{\mathrm{A}}$ & 0.034 \\
Priced portion of productivity shocks & $A_{0} / W_{0}$ & 0.384 \\
Initial productivity level over wage level & $\lambda$ & 2.075 \\
Annual firm death rate & & 0.010 \\
Stochastic Discount Factor & $r$ & \\
Risk-free rate & $\eta$ & 0.010 \\
Price of risk & & 0.800 \\
\hline
\end{tabular}


Table XII

Moments from the Data and from the Model

This table compares moments from our calibrated model with those from the data. Simulated data from the model are generated from 10,000 panels of 10,000 firms over 1,200 months (only the last year is used in the analyses). Targeted moments from the data are in bold.

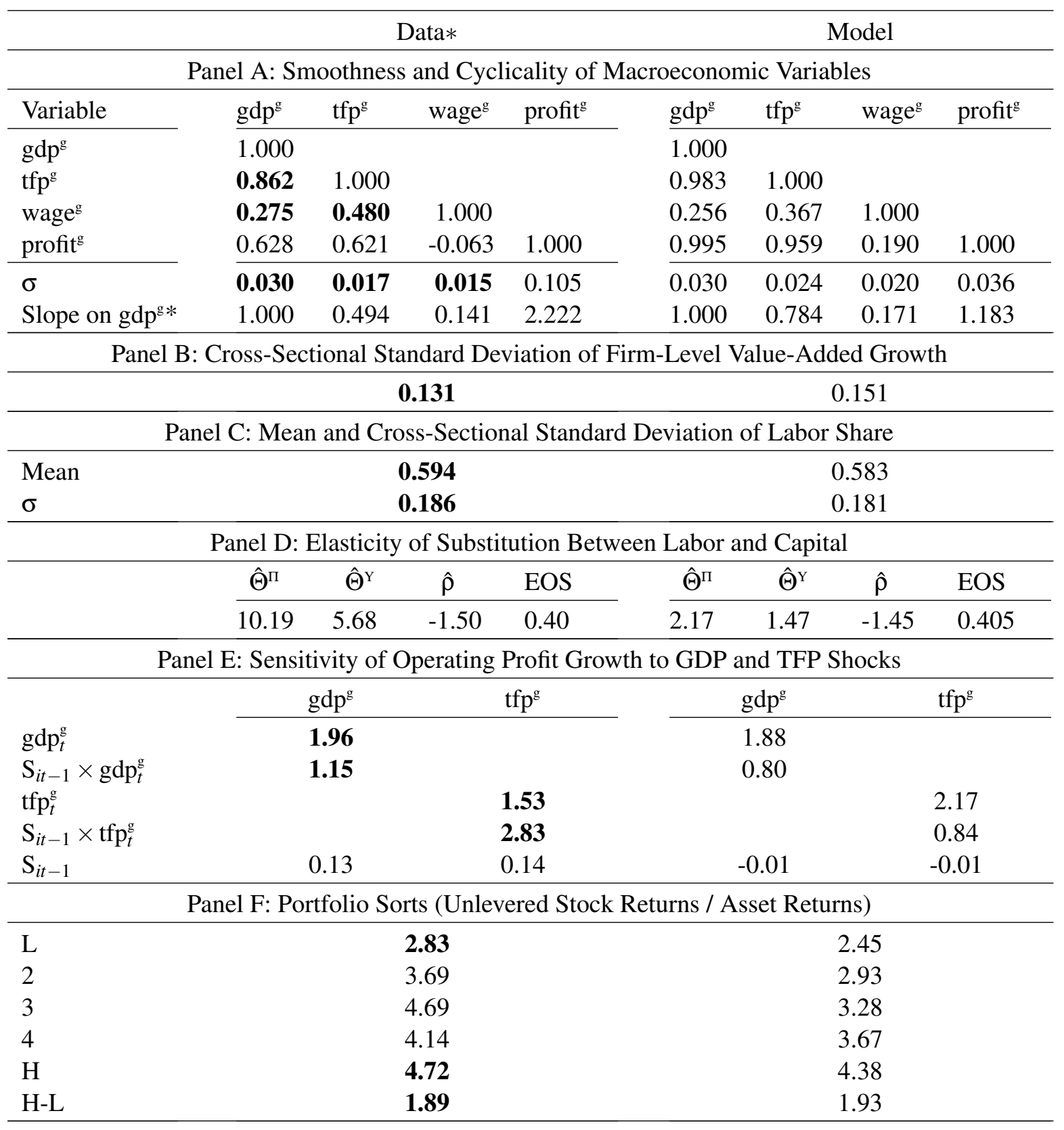

* Values in bold are target moments of the model calibration. 


\section{Working Paper Series}

A series of research studies on regional economic issues relating to the Seventh Federal Reserve District, and on financial and economic topics.

The Effects of the Massachusetts Health Reform on Financial Distress

WP-14-01

Bhashkar Mazumder and Sarah Miller

Can Intangible Capital Explain Cyclical Movements in the Labor Wedge?

WP-14-02

François Gourio and Leena Rudanko

Early Public Banks

William Roberds and François R. Velde

WP-14-03

Mandatory Disclosure and Financial Contagion

WP-14-04

Fernando Alvarez and Gadi Barlevy

The Stock of External Sovereign Debt: Can We Take the Data at 'Face Value'?

WP-14-05

Daniel A. Dias, Christine Richmond, and Mark L. J. Wright

Interpreting the Pari Passu Clause in Sovereign Bond Contracts:

It's All Hebrew (and Aramaic) to Me

WP-14-06

Mark L. J. Wright

AIG in Hindsight

WP-14-07

Robert McDonald and Anna Paulson

WP-14-08

On the Structural Interpretation of the Smets-Wouters "Risk Premium" Shock

Jonas D.M. Fisher

Human Capital Risk, Contract Enforcement, and the Macroeconomy

WP-14-09

Tom Krebs, Moritz Kuhn, and Mark L. J. Wright

Adverse Selection, Risk Sharing and Business Cycles

WP-14-10

Marcelo Veracierto

Core and 'Crust': Consumer Prices and the Term Structure of Interest Rates

WP-14-11

Andrea Ajello, Luca Benzoni, and Olena Chyruk

The Evolution of Comparative Advantage: Measurement and Implications

WP-14-12

Andrei A. Levchenko and Jing Zhang

Saving Europe?: The Unpleasant Arithmetic of Fiscal Austerity in Integrated Economies

WP-14-13

Enrique G. Mendoza, Linda L. Tesar, and Jing Zhang

Liquidity Traps and Monetary Policy: Managing a Credit Crunch

WP-14-14

Francisco Buera and Juan Pablo Nicolini 


\section{Working Paper Series (continued)}

Quantitative Easing in Joseph's Egypt with Keynesian Producers

WP-14-15

Jeffrey R. Campbell

Constrained Discretion and Central Bank Transparency

WP-14-16

Francesco Bianchi and Leonardo Melosi

Escaping the Great Recession

WP-14-17

Francesco Bianchi and Leonardo Melosi

More on Middlemen: Equilibrium Entry and Efficiency in Intermediated Markets

WP-14-18

Ed Nosal, Yuet-Yee Wong, and Randall Wright

Preventing Bank Runs

WP-14-19

David Andolfatto, Ed Nosal, and Bruno Sultanum

The Impact of Chicago's Small High School Initiative

WP-14-20

Lisa Barrow, Diane Whitmore Schanzenbach, and Amy Claessens

Credit Supply and the Housing Boom

Alejandro Justiniano, Giorgio E. Primiceri, and Andrea Tambalotti

WP-14-21

The Effect of Vehicle Fuel Economy Standards on Technology Adoption

WP-14-22

Thomas Klier and Joshua Linn

What Drives Bank Funding Spreads?

WP-14-23

Thomas B. King and Kurt F. Lewis

Inflation Uncertainty and Disagreement in Bond Risk Premia

Stefania D'Amico and Athanasios Orphanides

WP-14-24

Access to Refinancing and Mortgage Interest Rates:

WP-14-25

HARPing on the Importance of Competition

Gene Amromin and Caitlin Kearns

Private Takings

WP-14-26

Alessandro Marchesiani and Ed Nosal

Momentum Trading, Return Chasing, and Predictable Crashes

WP-14-27

Benjamin Chabot, Eric Ghysels, and Ravi Jagannathan

Early Life Environment and Racial Inequality in Education and Earnings in the United States

WP-14-28

Kenneth Y. Chay, Jonathan Guryan, and Bhashkar Mazumder

Poor (Wo)man's Bootstrap

WP-15-01

Bo E. Honoré and Luojia Hu

Revisiting the Role of Home Production in Life-Cycle Labor Supply

WP-15-02

R. Jason Faberman 


\section{Working Paper Series (continued)}

Risk Management for Monetary Policy Near the Zero Lower Bound

WP-15-03

Charles Evans, Jonas Fisher, François Gourio, and Spencer Krane

Estimating the Intergenerational Elasticity and Rank Association in the US:

Overcoming the Current Limitations of Tax Data

WP-15-04

Bhashkar Mazumder

External and Public Debt Crises

WP-15-05

Cristina Arellano, Andrew Atkeson, and Mark Wright

The Value and Risk of Human Capital

WP-15-06

Luca Benzoni and Olena Chyruk

Simpler Bootstrap Estimation of the Asymptotic Variance of U-statistic Based Estimators

WP-15-07

Bo E. Honoré and Luojia Hu

Bad Investments and Missed Opportunities?

Postwar Capital Flows to Asia and Latin America

Lee E. Ohanian, Paulina Restrepo-Echavarria, and Mark L. J. Wright

WP-15-08

Backtesting Systemic Risk Measures During Historical Bank Runs

Christian Brownlees, Ben Chabot, Eric Ghysels, and Christopher Kurz

WP-15-09

What Does Anticipated Monetary Policy Do?

Stefania D'Amico and Thomas B. King

Firm Entry and Macroeconomic Dynamics: A State-level Analysis

WP-16-01

François Gourio, Todd Messer, and Michael Siemer

Measuring Interest Rate Risk in the Life Insurance Sector: the U.S. and the U.K.

WP-16-02

Daniel Hartley, Anna Paulson, and Richard J. Rosen

Allocating Effort and Talent in Professional Labor Markets

WP-16-03

Gadi Barlevy and Derek Neal

The Life Insurance Industry and Systemic Risk: A Bond Market Perspective

WP-16-04

Anna Paulson and Richard Rosen

Forecasting Economic Activity with Mixed Frequency Bayesian VARs

WP-16-05

Scott A. Brave, R. Andrew Butters, and Alejandro Justiniano

Optimal Monetary Policy in an Open Emerging Market Economy

WP-16-06

Tara Iyer

Forward Guidance and Macroeconomic Outcomes Since the Financial Crisis

Jeffrey R. Campbell, Jonas D. M. Fisher, Alejandro Justiniano, and Leonardo Melosi

WP-16-07 


\section{Working Paper Series (continued)}

Insurance in Human Capital Models with Limited Enforcement

WP-16-08

Tom Krebs, Moritz Kuhn, and Mark Wright

Accounting for Central Neighborhood Change, 1980-2010

WP-16-09

Nathaniel Baum-Snow and Daniel Hartley

The Effect of the Patient Protection and Affordable Care Act Medicaid Expansions on Financial Wellbeing

Luojia Hu, Robert Kaestner, Bhashkar Mazumder, Sarah Miller, and Ashley Wong

WP-16-10

The Interplay Between Financial Conditions and Monetary Policy Shock

WP-16-11

Marco Bassetto, Luca Benzoni, and Trevor Serrao

Tax Credits and the Debt Position of US Households

WP-16-12

Leslie McGranahan

The Global Diffusion of Ideas

WP-16-13

Francisco J. Buera and Ezra Oberfield

Signaling Effects of Monetary Policy

WP-16-14

Leonardo Melosi

Constrained Discretion and Central Bank Transparency

WP-16-15

Francesco Bianchi and Leonardo Melosi

Escaping the Great Recession

WP-16-16

Francesco Bianchi and Leonardo Melosi

The Role of Selective High Schools in Equalizing Educational Outcomes:

Heterogeneous Effects by Neighborhood Socioeconomic Status

WP-16-17

Lisa Barrow, Lauren Sartain, and Marisa de la Torre

Monetary Policy and Durable Goods

WP-16-18

Robert B. Barsky, Christoph E. Boehm, Christopher L. House, and Miles S. Kimball

Interest Rates or Haircuts?

Prices Versus Quantities in the Market for Collateralized Risky Loans

WP-16-19

Robert Barsky, Theodore Bogusz, and Matthew Easton

Evidence on the within-industry agglomeration of R\&D, production, and administrative occupations

WP-16-20

Benjamin Goldman, Thomas Klier, and Thomas Walstrum

Expectation and Duration at the Effective Lower Bound

WP-16-21

Thomas B. King 


\section{Working Paper Series (continued)}

The Term Structure and Inflation Uncertainty

WP-16-22

Tomas Breach, Stefania D'Amico, and Athanasios Orphanides

The Federal Reserve's Evolving Monetary Policy Implementation Framework: 1914-1923

WP-17-01

Benjamin Chabot

Neighborhood Choices, Neighborhood Effects and Housing Vouchers

WP-17-02

Morris A. Davis, Jesse Gregory, Daniel A. Hartley, and Kegon T. K. Tan

Wage Shocks and the Technological Substitution of Low-Wage Jobs

WP-17-03

Daniel Aaronson and Brian J. Phelan

Worker Betas: Five Facts about Systematic Earnings Risk

WP-17-04

Fatih Guvenen, Sam Schulhofer-Wohl, Jae Song, and Motohiro Yogo

The Decline in Intergenerational Mobility After 1980

WP-17-05

Jonathan Davis and Bhashkar Mazumder

Is Inflation Default? The Role of Information in Debt Crises

WP-17-06

Marco Bassetto and Carlo Galli

Does Physician Pay Affect Procedure Choice and Patient Health?

Evidence from Medicaid C-section Use

WP-17-07

Diane Alexander

Just What the Nurse Practitioner Ordered:

Independent Prescriptive Authority and Population Mental Health

WP-17-08

Diane Alexander and Molly Schnell

How do Doctors Respond to Incentives?

Unintended Consequences of Paying Doctors to Reduce Costs

WP-17-09

Diane Alexander

Closing the Gap: The Impact of the Medicaid Primary Care Rate Increase on Access and Health Unintended Consequences of Paying Doctors to Reduce Costs

Diane Alexander and Molly Schnell

WP-17-10

Check Up Before You Check Out: Retail Clinics and Emergency Room Use

WP-17-11

Diane Alexander, Janet Currie, and Molly Schnell

The Effects of the 1930s HOLC "Redlining" Maps

WP-17-12

Daniel Aaronson, Daniel Hartley, and Bhashkar Mazumder

Inflation at the Household Level

WP-17-13

Greg Kaplan and Sam Schulhofer-Wohl 


\section{Working Paper Series (continued)}

The Effect of Fertility on Mothers' Labor Supply over the Last Two Centuries

WP-17-14

Daniel Aaronson, Rajeev Dehejia, Andrew Jordan, Cristian Pop-Eleches,

Cyrus Samii, and Karl Schulze

Financialization in Commodity Markets

WP-17-15

VV Chari and Lawrence J. Christiano

On Interest Rate Policy and Asset Bubbles

WP-17-16

Franklin Allen, Gadi Barlevy, and Douglas Gale

Estimating the Tax and Credit-Event Risk Components of Credit Spreads

WP-17-17

Luca Benzoni and Robert S. Goldstein

The Age-Time-Cohort Problem and the Identification of Structural Parameters in Life-Cycle Models

Sam Schulhofer-Wohl

WP-17-18

The Dire Effects of the Lack of Monetary and Fiscal Coordination

WP-17-19

Francesco Bianchi and Leonardo Melosi

Selecting Primal Innovations in DSGE Models

Filippo Ferroni, Stefano Grassi, and Miguel A. León-Ledesma

WP-17-20

The Tradeoffs in Leaning Against the Wind

WP-17-21

François Gourio, Anil K Kashyap, and Jae Sim

The Cross-Section of Labor Leverage and Equity Returns

WP-17-22

Andres Donangelo, François Gourio, Matthias Kehrig, and Miguel Palacios 